\title{
Erect wing regulates synaptic growth in Drosophila by integration of multiple signaling pathways Irmgard U Haussmann*, Kalpana White ${ }^{\dagger}$ and Matthias Soller*
}

Addresses: *School of Biosciences, University of Birmingham, Edgbaston, Birmingham, B15 2TT, UK. ${ }^{\dagger}$ Department of Biology and Volen Center for Complex Systems, Brandeis University, Waltham, MA 02454, USA.

Correspondence: Matthias Soller. Email: m.soller@bham.ac.uk

Published: 17 April 2008

Genome Biology 2008, 9:R73 (doi:10.1 I86/gb-2008-9-4-r73)

The electronic version of this article is the complete one and can be found online at http://genomebiology.com/2008/9/4/R73
Received: 15 October 2007

Revised: I 4 February 2008

Accepted: 17 April 2008

(C) 2008 Haussmann et al.; licensee BioMed Central Ltd.

This is an open access article distributed under the terms of the Creative Commons Attribution License (http://creativecommons.org/licenses/by/2.0), which permits unrestricted use, distribution, and reproduction in any medium, provided the original work is properly cited.

\begin{abstract}
Background: Formation of synaptic connections is a dynamic and highly regulated process. Little is known about the gene networks that regulate synaptic growth and how they balance stimulatory and restrictive signals.

Results: Here we show that the neuronally expressed transcription factor gene erect wing (ewg) is a major target of the RNA binding protein ELAV and that EWG restricts synaptic growth at neuromuscular junctions. Using a functional genomics approach we demonstrate that EWG acts primarily through increasing mRNA levels of genes involved in transcriptional and posttranscriptional regulation of gene expression, while genes at the end of the regulatory expression hierarchy (effector genes) represent only a minor portion, indicating an extensive regulatory network. Among EWG-regulated genes are components of Wingless and Notch signaling pathways. In a clonal analysis we demonstrate that EWG genetically interacts with Wingless and Notch, and also with TGF- $B$ and AP-I pathways in the regulation of synaptic growth.
\end{abstract}

Conclusion: Our results show that EWG restricts synaptic growth by integrating multiple cellular signaling pathways into an extensive regulatory gene expression network.

\section{Background}

Synaptic connections are formed during development and continue to be remodeled in the adult nervous system. Such morphological changes are implicated as the cellular basis of neuronal information processing and storage in the brain [1]. Although numerous molecules that affect synaptic growth have been identified, little is known about how expression of the genes encoding these is orchestrated by cellular signaling to regulate this form of synaptic plasticity.
Several signaling pathways with prominent roles in development have also been shown to regulate synaptic growth. These include Wnt/Wingless and transforming growth factor (TGF)- $\beta$ /bone morphogenetic protein (BMP) signaling pathways (reviewed in [2,3]), as well as the jun kinase pathway [4]. All of these pathways stimulate synaptic growth at neuromuscular junctions (NMJs) in Drosophila larvae [5-9], a model system for synaptic plasticity of glutamergic synapses [10]. In addition, Notch (N) signaling has recently also been implicated in plasticity due to impaired memory formation [11-13]. A major focus of these studies has been the 
identification of the transcription factors regulated by these signaling cascades. Prominent roles have been attributed to immediate early genes such as the transcription factors fos and jun [4,14-16], as well as the SMAD and co-SMAD homologues mad and medea in Drosophila [5-9]. Although much has been learned about how extracellular signals are transduced to the nucleus and regulate transcription factors, relatively little is known about gene networks and their organization, and how they operate in response to cellular signaling to mediate synaptic growth.

To delineate the nuclear response underlying presynaptic regulation of synaptic growth in a Drosophila model, we focused on the role of the transcription factor Erect wing (EWG), a homologoue of human NRF-1 [17,18]. A salient feature in the regulation of ewg expression is the elaborate control by ELAV, a post-transcriptional regulator expressed in neurons of Drosophila that is required for EWG protein expression [19-22]. The human homologue of ELAV, HuD, has previously been implicated in the regulation of synaptic plasticity [20,23], but the molecular and cellular consequences of increased expression of $\mathrm{HuD}$ are largely unknown. Consistent with a potential role in presynaptically regulating synaptic growth, EWG protein is expressed in all neurons, and transiently also in indirect flight muscles $[17,24,25]$. ewg mutant embryos are unable to exhibit coordinate larval movements and fail to hatch.

Here we show that the transcription factor gene ewg is a major target of the RNA binding protein ELAV and that EWG restricts synaptic growth at NMJs. This novel pathway primarily acts through EWG-up-regulated genes involved in either transcriptional or post-transcriptional regulation of gene expression. Analysis of synaptic growth in mutants of genes differentially regulated in ewg ${ }^{l}$ mutants shows that these genes are involved in both stimulatory and restrictive pathways. We further show that ewg genetically interacts with multiple signaling pathways in synaptic growth regulation in Drosophila. Our data suggest, therefore, that multiple cellular signaling pathways are connected with EWG regulation of synaptic growth in an extensive regulatory gene network.

\section{Results \\ Erect wing restricts synaptic growth at neuromuscular junctions}

To examine ewg mutants for synaptic growth defects at third instar NMJs, we used a clonal analysis strategy in mosaic animals. For this analysis we made the following rescue construct, termed $e \mathrm{FeG}$. The ewg cDNA was flanked by FRT sites and fused to an elav promoter. To visualize recombination, the sequence of yeast GAL4 was inserted downstream of the FRT-ewg-FRT cassette. FLP/FRT mediated recombination will result in loss of the ewg cDNA and lead to expression of GAL4 in neurons that can be visualized in the presence of a $U A S-C D 8:: G F P$ transgene (Figure 1a,c,e-i) [17,24,25]. The functionality of $e \mathrm{Fe} \mathrm{G}$ is shown in a clone induced in photoreceptor neurons in ewg ${ }^{l 1}$, a null allele [24]. Upon loss of the ewg cDNA in the clone, CD8::GFP is expressed and EWG expression is lost (Figure $1 \mathrm{~b}, \mathrm{c}$ ). For the analysis of third instar NMJs, recombination was induced in late embryogensis (14$16 \mathrm{~h}$ after egg laying). Larvae bearing EWG null clones move indistinguishably from their balancer carrying siblings, pupate normally and many adults hatch. These adults are, however, impaired in walking.

At third instar NMJs, EWG deficient motorneurons have an increased number of synaptic boutons that look morphologically normal as visualized with an antibody against synaptotagmin, a marker for synaptic vesicles [26] (Figure 1d-i). Quantification of type $1 \mathrm{~b}$ boutons at muscle 13 revealed about an $85 \%$ increase in bouton number ( $p<0.0001$; Figure 1 j) compared to wild-type or balancer carrying siblings containing one wild-type copy of ewg (rec. control in Figure 1j). Since ewg is located on the $\mathrm{X}$ chromosome and we used males, we also quantified type $1 \mathrm{~b}$ bouton numbers at muscle 13 in ewg ${ }^{l}$ females transheterozygous for a hypomorphic $P$ element insertion, $P\left\{\right.$ lacW\}ewg ${ }^{G 1518}(18.8 \pm 0.45, \mathrm{n}=18, p<$ 0.0001 for comparison with wild type). Significant effects were also observed at muscles 4, 6/7 and 12 (29\%, 30\% and $45 \%$ increase compared to wild type, $p \leq 0.001$ ). Besides overgrowth, NMJs of EWG deficient clones appeared normal and staining with markers for active (Nc82) and periactive (Highwire) zones, for microtubules (Mab 22C10) or post-synaptic specializations (anti-DLG) did not reveal obvious differences (Figure 1k-n and data not shown). The role of EWG in synap-

\footnotetext{
Figure I (see following page)

Erect wing restricts synaptic growth at third instar neuromuscular junctions. (a) Schematic of the eFe $G$ construct used for clonal analysis of ewg ${ }^{\prime \prime}$, an embryonic lethal allele. (b,c) FLP/FRT mediated recombination in photoreceptor neurons in third instar larval eye disc. Note that CD8::GFP is expressed (c) in the ewgll clone (b). The scale bar in (c) is $25 \mu \mathrm{m}$. (d-i) NMJs of control and ewg II clones in third instar larvae. Clones of controls (d-f, in ewglleFeG/+; hs-flp/+ UAS-CD8::GFP/+ females, rec. control in (j)) and of ewgll (g-i, in ewglleFeG/Y; hs-flp/+ UAS-CD8::GFP/+ males) were stained with anti-SYT or with antiCD8 antibodies to visualize synaptic growth defects of type Ib boutons at muscle I3. The scale bar in (i) is $20 \mu \mathrm{m}$. (j) Quantification of synaptic growth defects in ewgl'mutant neurons. Shown are means of bouton numbers (type Ib at muscle I3) with standard errors ( $\mathrm{n}=2 \mathrm{I}-35$ ). Rec. control refers to clones made in the presence of one copy of ewg ${ }^{+}$as in ewg/leFeG/+; hs-flp/+ UAS-CD8::GFP/+ females. Tetanus toxin was expressed from a UAS transgene in clones by the recombined $\mathrm{eFeG}$ construct. Statistical significance of differences from comparisons with wild type is shown on top of bars $(* * * p<0.000$ I, $*_{*}^{*} p<0.00 \mathrm{I}$, n.s. for non significant). Other relevant comparisons are marked by horizontal bars with the statistical significance indicated on the side. (k-n) Distribution of synaptic markers is normal at ewgl/NMJs. Active zones were stained with anti-Nc82 at wild type (k) or ewgl/NMJs (m) and periactive zones were stained with anti-Highwire at wild type (I) or ewg ${ }^{\prime \prime N M J s ~(n) . ~ T h e ~ s c a l e ~ b a r ~ i n ~(n) ~ i s ~ I ~} \mu \mathrm{m}$.
} 


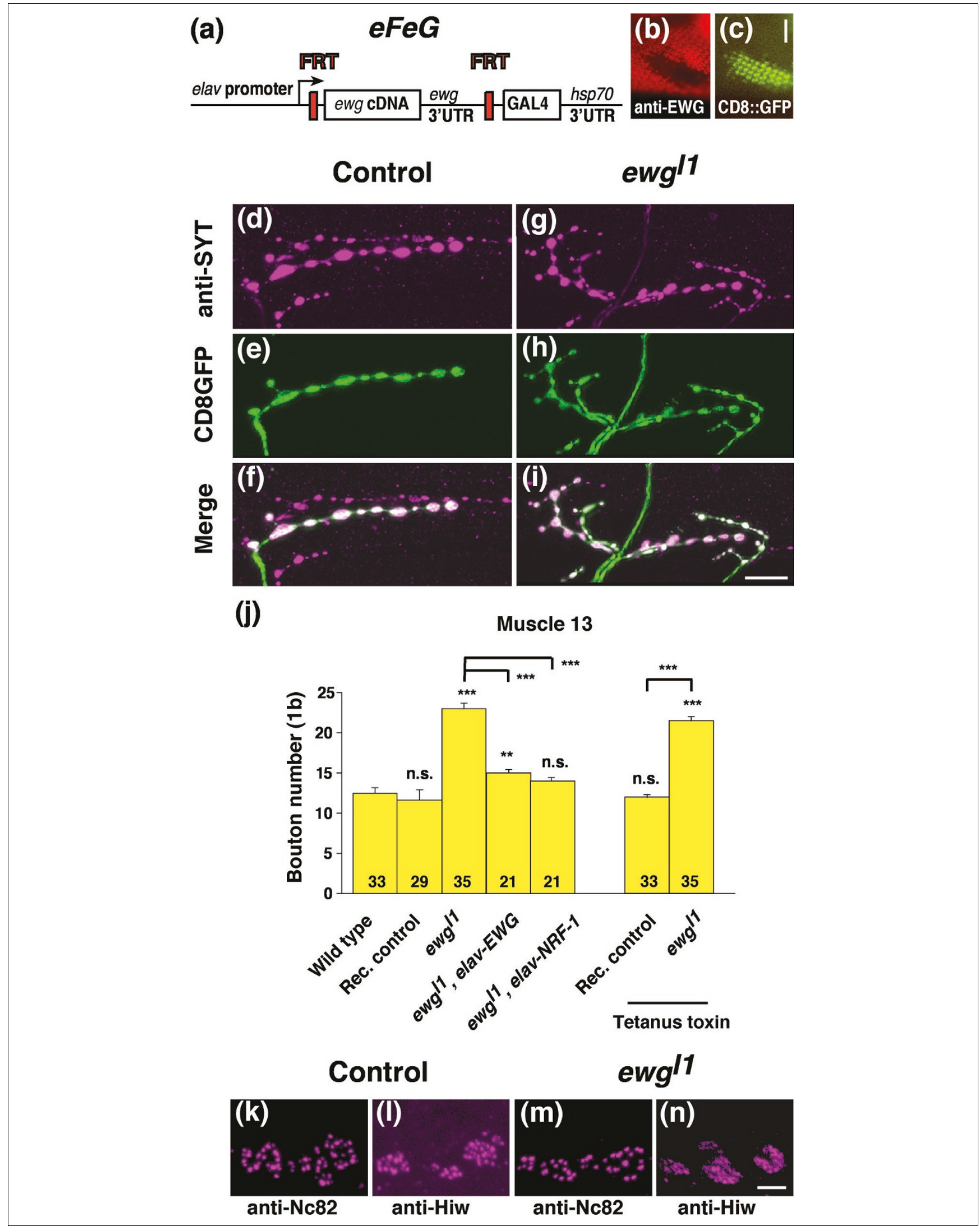

Figure I (see legend on previous page) 
tic growth regulation is cell-autonomous, since bouton numbers of non-recombined neurons in mosaic animals were indistinguishable from wild type (data not shown). Inhibition of synaptic transmission by expression of tetanus toxin in EWG deficient neurons did not affect overgrowth, demonstrating that overgrowth is not a result of compensatory signals from the muscle due to changes in neuronal activity (Figure 1j). Similarly, expression of tetanus toxin also did not affect synaptic growth in wild-type clones (Figure 1j).

To demonstrate that synaptic overgrowth of EWG deficient neurons is a result of ewg loss of function (LOF), we added a rescue construct where an elav promoter drives the ewg cDNA (elav-EWG) [17]. Presence of this construct significantly reduced the number of type $1 \mathrm{~b}$ boutons at muscle 13 compared to EWG deficient neurons ( $p<0.0001$; Figure 1f), but rescue is not complete compared to wild-type neurons ( $p$ $<$ 0.001; Figure 1f). Since ewg is strongly homologous to human NRF-1 (80\% in the DNA binding domain [18]), we tested if expression of NRF-1 under an elav promoter can rescue the synaptic growth defect of ewg. elav-NRF-1 transgenes fully rescued synaptic growth defects of ewg ${ }^{l}$ mutants $(p<$ o.0001), resulting in bouton numbers that were not significantly different from wild type (Figure $1 \mathrm{j}$ ). elav-NRF-1 transgenes also fully rescued embryonic lethality of ewg ${ }^{l}$ mutant embryos ( $89 \pm 8 \%, \mathrm{n}=5$ independent transgene insertions). ewglielav-NRF-1 animals develop to pharate adults, but fail to hatch.

Since ewg LOF results in synaptic overgrowth, we wanted to know if overexpression of ewg results in reduced synaptic growth. To separate ewg function in early neuronal differentiation from its role in synaptic growth regulation and to apply physiological concentrations of EWG, we used an inducible neuron-specific GAL4 driver (elav-GeneSwitch$G A L 4$, elav-GS-GAL4 [27]) to express EWG from a $U A S-e w g$ transgene. Concentration dependent inducibility of the elavGS-GAL4 was verified by western blots (Figure 2a). At NMJs, numbers of type $1 \mathrm{~b}$ boutons at muscle 13 were about $30 \%$ reduced compared to wild type, and at muscle 12 about $45 \%$ reduced ( $p<0.0001$; Figure $2 b-d$ ) when EWG expression was about two-fold increased compared to wild type (Figure 2a, lane 3 versus lane 2). Higher expression levels of EWG did not further reduce synaptic growth, but resulted in pupal lethality. Controls with induced elav-GS-GAL4 (but no UAS$e w g$ ), or $U A S-e w g$ alone had wild-type bouton numbers (data not shown).

\section{ewg is a major ELAV target in post-embryonic development}

In the presence of the RNA binding protein ELAV, the last ewg intron is spliced, resulting in expression of EWG protein $[19,21]$. Since the ewg gene encodes a transcription factor, EWG could potentially regulate a large portion of genes that are also regulated by ELAV, and therefore rescue elav mutants. To test if elav mutants are rescued by EWG, we used animals transheterozygous for the elav ${ }^{t s} 1$ temperature sensitive allele and for the null allele elaves[28]. When early functions of ELAV in neuronal differentiation were allowed by rearing embryos at the permissive temperature, elav-EWG fully rescued the lethality of elav ${ }^{t s 1} / e^{2} l a v^{e 5 f l i e s}$ (Figure $3 \mathrm{a}$ ). The rescued elavtsi/elave5; elav-EWG animals, however,

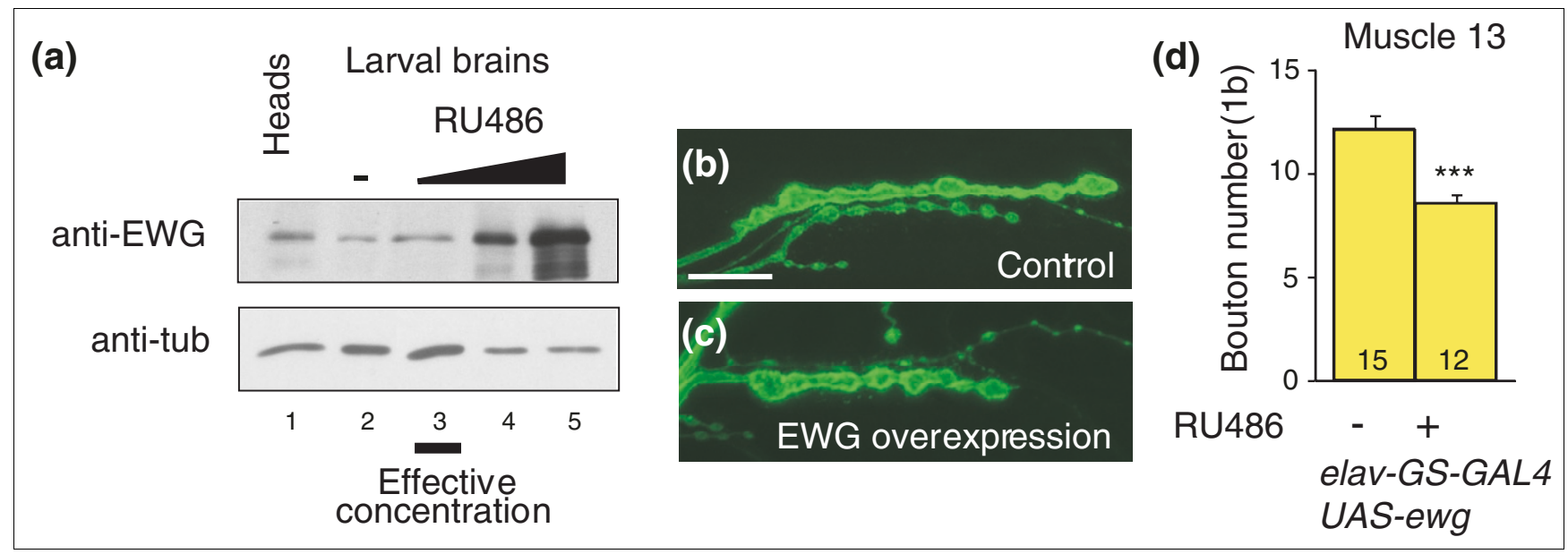

Figure 2

Conditional overexpression of ewg reduces synaptic growth. (a) Western blot of EWG in larval brains upon induced expression. EWG levels in larval brains were compared between elav-GS-GAL4 UAS-ewg animals fed with RU486 ( $1.2,4.8$ and $19.2 \mu \mathrm{g} / 10 \mathrm{ml}$ food, lanes 3-5) and uninduced animals (lane 2), and to adult heads (lane I). Note that a two-fold overexpression of EWG is effective to reduce synaptic growth (lane 3) compared to wild type (lane 2). (b,c) NMJs of control and EWG overexpressing animals. Shown are NMJs at muscle 13 of uninduced (b) or induced (c, $1.2 \mu \mathrm{g} \mathrm{RU486/10} \mathrm{ml} \mathrm{food)} \mathrm{elav-GS-}$ GAL4 UAS-ewg animals stained with anti-HRP antibodies. The scale bar in (b) is $20 \mu \mathrm{m}$. (d) Quantification of synaptic growth defects with excess EWG. Shown are means of bouton numbers (type Ib at muscle I3) with standard errors $(\mathrm{n}=12-15)$ of uninduced (b) or induced (c, I.2 $\mu \mathrm{g} R U 486 / \mathrm{I} 0 \mathrm{ml}$ food) elav-GS-GAL4 UAS-ewg animals. Statistically significant differences are indicated by asterisks $(* * * p<0.0001)$. 
showed motor defects and were flightless, suggesting that the RNA binding protein ELAV regulates additional genes. Given the prominent NMJ phenotype of ewg mutants, we next tested if ELAV is also involved in regulating synaptic growth. At NMJs, elavts1/elave5animals showed a significant reduction of bouton numbers compared to wild type $(p<0.0001$; Figure 3c,f), a phenotype opposite to the ewg mutant phenotype. Synaptic growth defects of elavts1/elave5animals, however, were fully rescued to wild-type levels by an elav-EWG transgene ( $p<0.0001$ for elav ${ }^{\text {ts1 }} /$ elav $^{e 5}$; elav-EWG compared

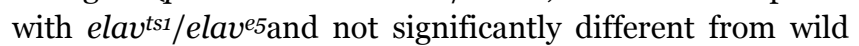
type; Figure 3d,f). As expected, an elav-ELAV transgene also fully rescued synaptic growth defects of elav ${ }^{t s 1} / e^{2} l a v^{e} 5$ animals ( $p<0.0001$ for elav ${ }^{\text {ts1 }} /$ elav $^{\text {e5}}$; elav-ELAV compared with

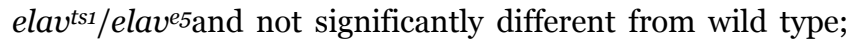
Figure 3d,f). These results indicate overlapping stimulatory and restrictive pathways in regulating synaptic growth that are integrated through the transcriptional regulator EWG (see below). Boutons in elav ${ }^{\text {ts1 }} / e^{e l a v}$ 5animals appeared normal and staining with markers for active ( Nc82) and periactive (Highwire) zones, for microtubules (Mab 22C10) or post- synaptic specializations (anti-DLG) did not reveal obvious differences (data not shown).

\section{Identification of genes differentially regulated in ewg'lmutants}

To assess how the transcription factor EWG regulates synaptic growth, we identified genes differentially regulated in ewglimutants using cDNA microarrays. We hand-selected ewg $g^{l}$ late stage embryos that differ from their siblings by the lack of green fluorescent protein (GFP), extracted and amplified polyA RNA, and hybridized cDNA microarrays. To exclude genes differentially regulated due to genetic background and to validate genes differentially regulated in $e w g^{l}$ mutants at a genomic scale, we included $e w g^{l}$ animals rescued by elav-EWG. From these experiments ( $\mathrm{n}=4$, except for $e w g^{l l} \mathrm{n}=5$ ), mRNA expression levels of 107 genes were significantly down-regulated (Figure 4c) and of 107 genes were significantly up-regulated (Figure 4d) in ewg ${ }^{l}$ embryos ( $p \leq$ o.01; changes in expression levels are shown in Table $\mathrm{S}_{3}$ of Additional data file 1) compared to both wild-type and ewglelav-EWG embryos. Quantitative RT-PCR analysis from selected genes that were down-regulated (Ac3, CG7646, (a)

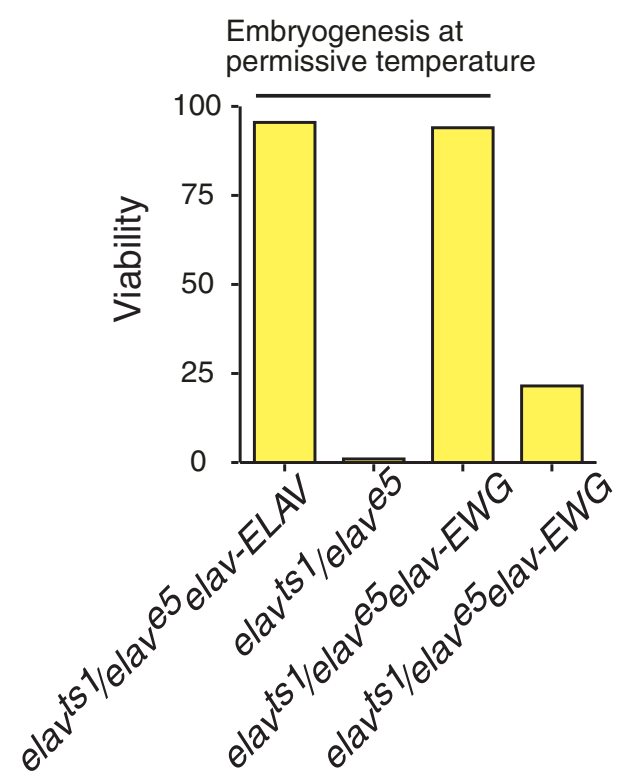

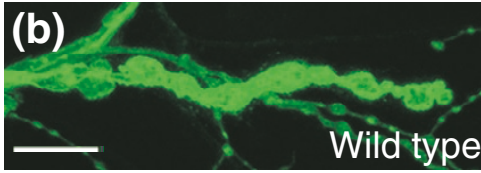
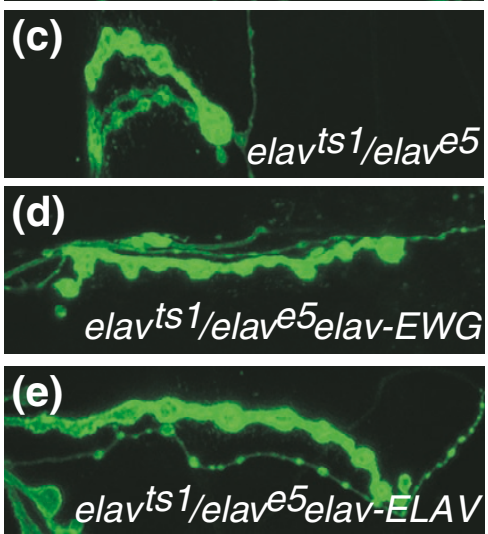

(f)

Muscle 13

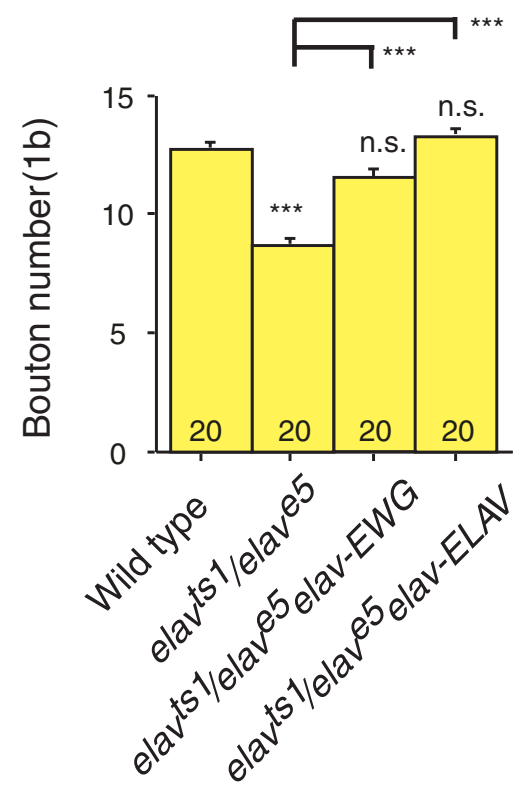

\section{Figure 3}

Erect wing rescues viability and synaptic growth defects of elav mutants. (a) Rescue of viability of elav mutants by ewg transgenes. An elav-EWG transgene fully rescues viability of a temperature sensitive elav allele (elavis / transheterozygous for the elave5, a null allele); when early functions in neuronal differentiation are provided by rearing flies at the permissive temperature (three days at $18^{\circ} \mathrm{C}$ and then at $25^{\circ} \mathrm{C}, \mathrm{n}=250-350$ animals per genotype). (b-f) Rescue of synaptic growth defects of elav mutants by EWG. Synaptic growth in elavts//elaves mutants $(c, f)$ is significantly reduced $(p$ ? $0.000 \mathrm{I})$ when reared at the restrictive temperature during larval life compared to wild type $(b, f)$ and is rescued by elav-EWG $(d, f)$ and elav-ELAV (e,f). Bouton numbers (type Ib at muscle 13$)$ in $(f)$ are shown as means with standard errors $(n=21-35)$. Statistical significance of differences from comparisons with wild type is shown on top of bars $(* * * p<0.000$ I, n.s. for non significant). Other relevant comparisons are marked by horizontal bars with the statistical significance indicated on the side. The scale bar in (b) is $20 \mu \mathrm{m}$. 


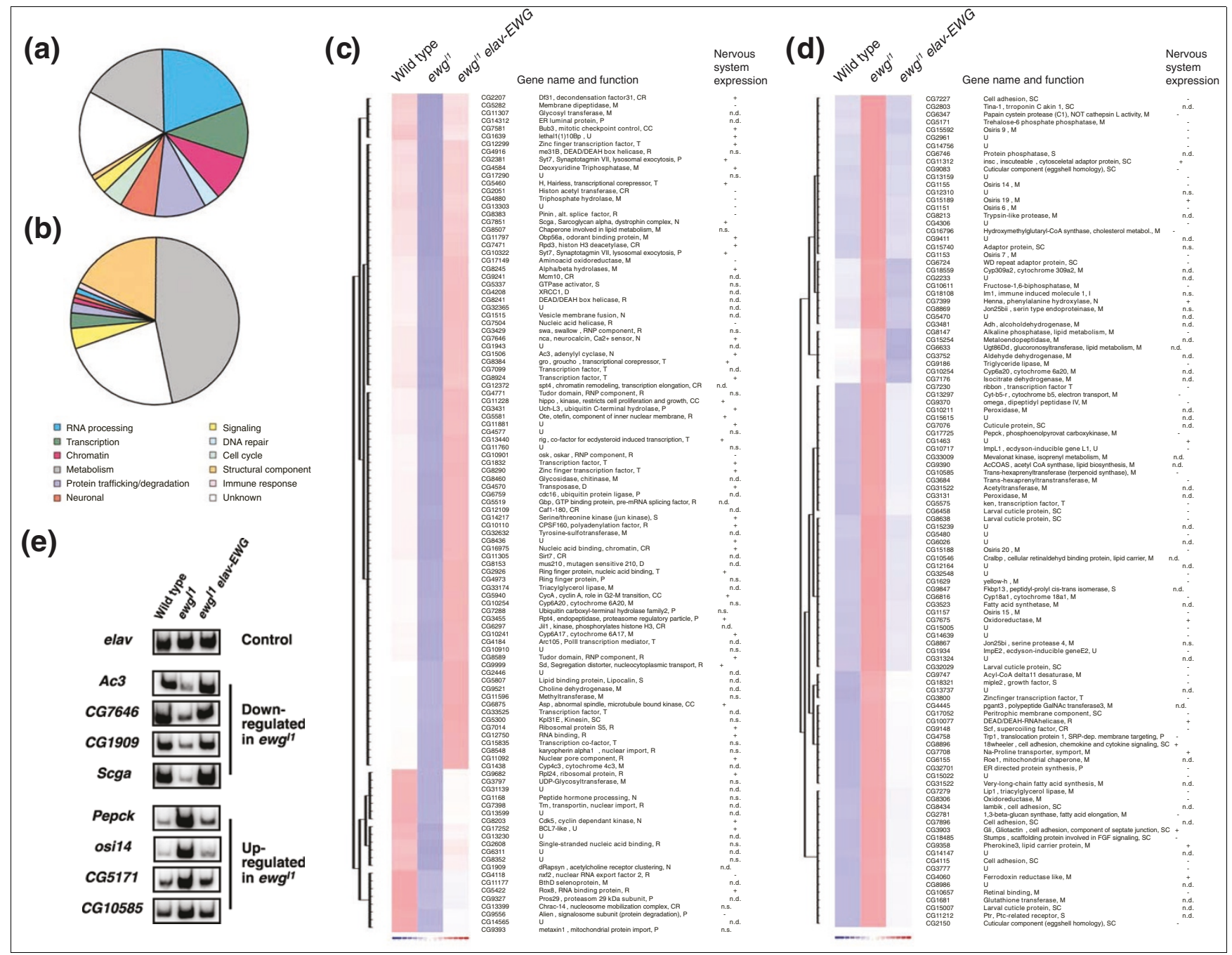

Figure 4

Genes differentially regulated in late embryos of ewg $/$ mutants. (a,b) Functional classification of genes differentially regulated in late embryos of ewg ${ }^{\prime \prime}$ mutants. Down-regulated (a) and up-regulated (b) genes were classified according to Gene Ontology processes. (c,d) List of genes differentially regulated in late embryos of ewg $/$ mutants, giving functional classification and nervous system expression. Hierarchical clustering of normalized expression levels of down-regulated (c) and up-regulated (d) genes in ewg/lembryos compared with wild type and ewgllembryos rescued with elav-EWG. Gene names and functional categories are shown to the right together with nervous system expression data determined by RNA in situ hybridization (+, expressed in the nervous system; -, not expressed in the nervous system; n.s., no staining; n.d., not determined). Differential expression is visualized by blue (downregulation) and red (up-regulation). (e) Quantitative RT-PCR of selected genes differentially regulated in ewg $/ 1$ mutants. PCR products using ${ }^{32}$ P labeled forward primers from genes up-regulated in ewg IImutants Ac3, CG7646, CGI 909 and Srca (cycles 28, 24,28 and 28), and from genes down-regulated in ewgllmutants Pepck, osil 4, CG5I 7 I and CGI0585 (cycles 26) were analyzed on 6\% polyacrylamide gels. elav: control (cycle 28).

CG1909, Srca) or up-regulated (Pepck, osi14, CG5171, CG10585) in ewglimutant embryos further confirmed the findings from the microarray expression analysis (Figure 4e), for example, expression levels were reduced or increased in ewg ${ }^{l}$ mutant embryos compared to the control gene elav, but restored to wild-type levels in the presence of the elav-EWG transgene.

Clustering differentially regulated genes revealed that downregulated genes fall into several functional classes with a preference for genes involved in the regulation of gene expression (40\%, 43 of 107; Figure 4a,c), while up-regulated genes are enriched for genes involved in basic cellular metabolism (47\%, 50 of 107; Figure 4b,d). Surprisingly, only a minor portion of genes ( $4 \%, 8$ of 214; Figure 4c,d) could be loosely defined as 'neuronal effector genes' (genes at the end of the regulatory expression hierarchy in neurons and associated with neuron specific functions) with known or potential functions in synaptic growth regulation, for example, Ac3, encoding an adenylyl cyclase, CG1909, encoding a Drosophila Rapsyn homologue, $C G 7646$, encoding a $\mathrm{Ca}^{2+}$ sensor, and the gene encoding Henna, a phenylalanine hydroxylase involved in dopamine and serotonin synthesis. Candidates for mediating the synaptic growth phenotype from the remaining 
functional classes include groucho (gro), encoding a transcriptional repressor of $\mathrm{Wg}$ and $\mathrm{N}$ signaling, and genes encoding a number of cell adhesion molecules ( $C G 7227,18 w$, CG8434, CG7896, Gli, CG4115).

Synaptic growth defects in ewg mutants are cell-autonomous, suggesting that differentially expressed genes involved in regulating synaptic growth are also expressed in the nervous system. We therefore analyzed RNA expression patterns in late stage embryos from a representative number of genes differentially regulated in $\mathrm{ewg}^{l \mathrm{l}}$ mutants $(66 \%, 74$ down- and 68 up-regulated genes; RNA in situ expression patterns are mostly available from the Berkeley Drosophila Genome Project (BDGP)). RNA in situ hybridization experiments revealed that $86 \%$ (42 of 52 ) of down-regulated genes in ewg ${ }^{l}$ mutants, but only $17 \%$ (11 of 63) of up-regulated genes in ewg ${ }^{l}$ mutants, are expressed in the nervous system of late stage embryos (Figure 4c,d; Figures S2 and S3 in Additional data file 1). Interestingly, these RNA in situ hybridization experiments further revealed that the vast majority of genes down-regulated in ewg ${ }^{l}$ mutants are broadly expressed in the entire nervous system, suggesting that they might be direct targets of EWG. From those genes where the RNA expression pattern was analyzed, 30\% (22 of 74) of down-regulated genes in ewg ${ }^{l}$ mutants and $7 \%$ (5 of 68) of up-regulated genes in ewg ${ }^{l}$ mutants did not yield a signal in RNA in situ experiments, although they were detected on microarrays at comparable levels. These transcripts might reside, therefore, in tightly packed mRNP particles and not be accessible to in situ hybridization after fixation, which has been shown, for example, for Fragile X Mental Retardation Protein (FMRP) mRNA in dendrites [29].

\section{Analysis of synaptic growth in mutants of genes differentially regulated in ewg"'mutants}

Recent efforts in Drosophila genome projects have increased the number of mutants to cover $50-60 \%$ of all protein coding genes [30-34]. This allows for a functional genomics approach to identify a representative fraction of genes differentially regulated in ewg $g^{l}$ mutants and involved in synaptic growth regulation, and to elucidate general principles that operate in this biological process. We obtained viable mutants for $42 \%$ (40 of 95) of genes down-regulated in $e w g^{l i}$ mutants and for $37 \%$ (23 of 62) of genes up-regulated in ewg ${ }^{l}$ mutants (Table S2 in Additional data file 1). Focusing on synaptic growth regulation, we restricted our analysis to genes not involved in basic cellular metabolism unless their expression was enriched in the nervous system. Most of the mutants were $P$ element or piggyBAC insertions in promotor regions and represent hypomorphic alleles indicated by $38 \%$ (21 from 57) showing adult phenotypes (pupal lethality, morphological aberrations, sterility or flightlessness; Table S2 in Additional data file 1) as transheterozygotes over a deficiency or a second allele. A minor portion of mutants was embryonic or early larval lethal (10\%, 7 of 70$)$ and could not be analyzed for synaptic growth defects. Viable mutants tend to accumulate genetic modifiers [35]. Therefore, we normalized the genetic background by analyzing transheterozygotes for a chromosomal deficiency, or in some cases transheterozygotes for a second allele. Since the most pronounced effect in ewg ${ }^{l}$ mutants was at muscle 13 , we quantified type $1 \mathrm{~b}$ boutons at muscle 13 .

Analysis of synaptic growth in mutants of genes down- and up-regulated in ewg ${ }^{l i}$ mutants revealed that $85 \%$ (34 of 40) and $70 \%$ (16 of 23), respectively, were associated with statistically significant differences in synaptic growth compared to controls (Figure 5, $y w$ line and $y w$ transheterozygous for appropriate deficiencies, $p \leq 0.0001$ for the vast majority; for details, see Table S2 in Additional data file 1). Ninety percent (18 of 20) of the genes down-regulated in ewg ${ }^{l}$ mutants are also expressed in the nervous system (Figure 5a,c). Clustering these genes into functional classes revealed a strong enrichment for genes involved in the regulation of gene expression (65\%, 22 of 34; Figure 5a,c). In contrast, genes up-regulated in $e w g^{l}$ mutants with synaptic growth defects are mostly not expressed in the nervous system (64\%, 7 of 11; Figure 5b,c) and are split into many different functional classes (Figure $5 \mathrm{~b}, \mathrm{c})$.

For both down- and up-regulated genes in ewg ${ }^{l}$ mutants with synaptic growth defects, phenotypes could be split into groups with either more or less boutons (Figure 5). Among those genes down-regulated in ewg ${ }^{l}$ mutants with growth defects in mutants, 29\% (10 of 34) had the same overgrowth phenotype as ewglimutants (Figure 5 a). These results show that EWG-regulated gene expression combines both stimulatory and restrictive functions in synaptic growth regulation, and that restrictive functions dominate, indicated by the overgrowth phenotype of ewg ${ }^{l}$ mutants.

Based on synaptic growth phenotypes associated with mutants of genes differentially regulated in ewg $g^{l 1}$ mutants, the following model assigns more distinct roles to these genes in the context of EWG regulation (Figure 5c). Genes down-regulated in ewg ${ }^{l i}$ mutants with an increased number of boutons exert restriction on synaptic growth in the presence of EWG, while those genes down-regulated in ewglmutants with a reduced number of boutons in mutants might provide a trophic supply for synaptic growth. For genes up-regulated in ewg ${ }^{l i}$ mutants, overgrowth associated with mutations in these genes is indicative of a role in expansion of synaptic growth as they are repressed in the presence of EWG. This class includes primarily cell adhesion molecules for which a restrictive role has been demonstrated when adhesion has been increased (for example, [36]). Most genes up-regulated in ewg ${ }^{l}$ mutants with fewer boutons are not expressed in the nervous system. These genes might, therefore, be regulated endocrinologically, indicated by the role of ewg in regulating metabolic aspects. 


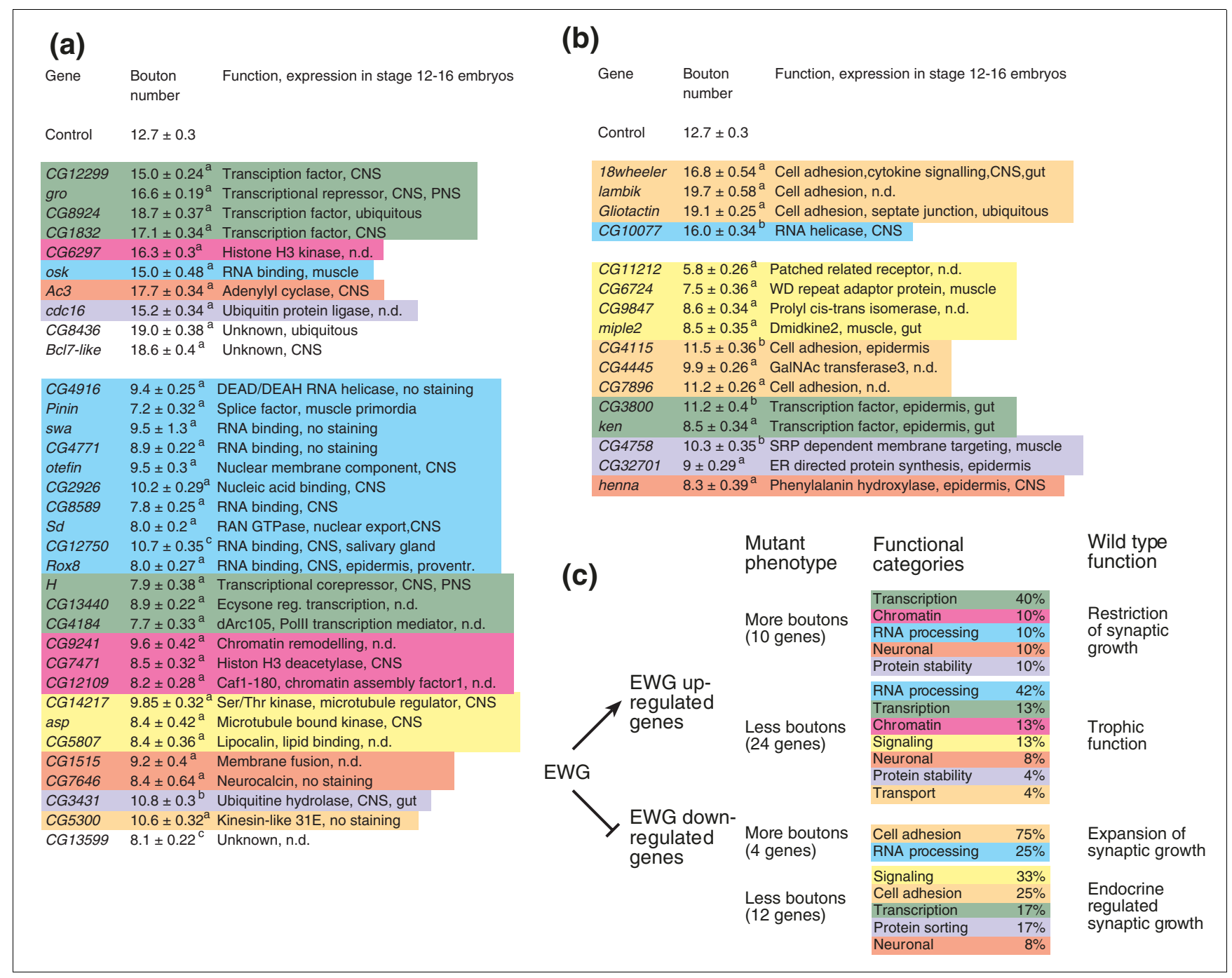

\section{Figure 5}

Analysis of synaptic growth in mutants of genes differentially regulated in ewg $g^{\prime \prime}$ mutants. (a,b) Quantification of synaptic growth in mutants of genes differentially regulated in ewg $/$ mutants. Type Ib boutons at muscle 13 were quantified and are shown as means with standard error $(n=18-22)$ in transheterozygotes for either a chromosomal deficiency or a second allele from mutants of genes down-regulated (a) or up-regulated (b) in ewg II mutants that were significantly different ( $a p$ ? 0.000I, bp ? 0.00I, $c p$ ? 0.05) compared to controls ( $y w$ and $y w$ transheterozygous for the corresponding chromosomal deficiency) except for genes involved in basal metabolism. Detailed genotypes with corresponding bouton numbers are listed in Table $\mathrm{S} 2$ in Additional data file I. Genes are clustered according to their function with the color codes used in Figure 4 . Note that genes down-regulated in ewgllmutants are highly enriched for expression in the nervous system $(90 \%)$ while only a minor portion of genes up-regulated in ewg $/$ mutants is expressed in the nervous system (36\%). (c) Summary of mutants in genes differentially regulated in ewg $g^{\prime \prime}$ mutants with synaptic growth defects and model of EWG regulation of these genes and their roles in synaptic growth regulation. CNS, central nervous system; PNS, peripheral nervous system.

\section{Erect wing co-regulated genes are functionally related} Pioneering work in yeast has shown that expression of functionally related genes is co-regulated (reviewed in [37]). We therefore used genetic interaction experiments to test for functional connections among genes that are differentially expressed in ewg mutants and that are also involved in synaptic growth regulation. Since loss of ewg results in more boutons and synaptic overgrowth can be further induced (for example, by overexpression of the fos and jun heterodimer $\mathrm{AP}-1$, see below), we analyzed double mutants in a representative number of those genes down-regulated in ewg ${ }^{l}$ mutants with more boutons. For all different combinations tested, none of the double mutant animals had more boutons than the single mutants, indicating that these genes do not act in parallel to regulate synaptic growth as independent effects would be additive (Table $\mathrm{S} 1$ in Additional data file 1). Some combinations, however, resulted in significant reduction of bouton numbers (for example,Ac3; Bcl7-like, Ac3; CG1943, and Bcl7-like; CG12299; Table S1 in Additional data file 1), suggesting that a combined loss of function in these genes might affect trophic supply to synaptic growth. 
Next, we validated functional connections among genes down-regulated in ewg ${ }^{l}$ mutants with a synaptic overgrowth phenotype in another assay. One of the genes in this class is gro, for which hypomorphic alleles are known that are associated with an overproliferation of frontal bristles on the head (Figure 6b). gro has been described as a transcriptional corepressor that interacts with a subset of negative transcriptional regulators [38]. We therefore tested a representative number of mutants in genes downregulated in ewg ${ }^{l i}$ mutants in combination with gro for a change of the gro bristle phenotype. All mutants tested genetically interacted with gro, resulting in either an enhancement or suppression of the gro bristle phenotype (Figure 6e). None of the single mutants had more bristles, but some had less (Figure 6d), suggesting that the gro phenotype can be suppressed (for example, CG8924 and Bcl7-like), indicated by several roles of gro in peripheral nervous system specification [39]. With quantitative RTPCR, we verified differential expression of these genes in ewg ${ }^{l}$ mutants and rescue to wild-type expression levels by the presence of an elav-EWG transgene in ewg ${ }^{l}$ mutants (Figure 6f). The genes are also expressed predominantly in the ventral nerve cord (Figure $\mathrm{S}_{3}$ in Additional data file 1; Figure 4c) [40]. Taken together, these data strongly suggest that these genes down-regulated in $\mathrm{ewg}^{\mathrm{l}}$ mutants are functionally connected and operate in a common pathway.

\section{erect wing genetically interacts with Notch and Wnt/ Wingless signaling in synaptic growth regulation}

The predominance of transcriptional and post-transcriptional regulators among genes differentially regulated in ewg ${ }^{l}{ }^{l}$ mutants, together with opposite phenotypes associated with mutants of these genes, suggests that overlapping stimulatory and restrictive pathways are integrated by an extensive regulatory gene network. This model for the regulation of synaptic growth implies that signaling pathways converge in the regulation of gene expression and predicts that ewg genetically interacts with several signaling pathways involved in regulating synaptic growth.

Groucho, the protein encoded by gro, is differentially regulated in ewg mutants and acts in both $\mathrm{N}$ and Wg signaling pathways [39,41,42]. Since Wg was previously shown to regulate synaptic growth [43], we first determined if $\mathrm{N}$ is also involved in regulating synaptic growth and second, if ewg genetically interacts with these two pathways. Therefore, we quantified type Ib bouton numbers at muscle 13 of third instar NMJs in the absence or presence of EWG using the $e \mathrm{FeG}$ transgene (Figure 1). In this genetic condition, half of the mosaic animals will have one copy of the wild-type ewg gene in clones while the other half contains the ewg ${ }^{l}$ null allele and, therefore, has no EWG protein in clones. Changes in $\mathrm{N}$ signaling were achieved through the recombined $e \mathrm{FeG}$ transgene that expresses GAL4 in the clone and drives either $U A S-N$ for N overexpression or $U A S-N-R N A i$ for N down-regulation. Expression of $U A S-N-R N A i$ in post-mitotic neurons has previously been shown to reduce $\mathrm{N}$ levels and to result in long-term memory deficits [11-13]. Changes in $w g$ signaling in clones was achieved through overexpression from UAS transgenes of $w g$ or pangolin (pan), the transcription factor intracellularly mediating the canonical wingless signal in embryos and wing discs [44-46].

Similar to ewg, N restricts synaptic growth, resulting in increased bouton numbers indicated by down-regulation of $N$ with RNA interference during larval life (from two independent $U A S$ inserts, $p=0.005$ for bar 1 compared with bar 4 , Figure $7 \mathrm{a})$ or in reduced bouton numbers when $\mathrm{N}$ was overexpressed ( $p<0.0001$ for bar 1 compared with bar 6, Figure $7 \mathrm{a})$ compared to wild-type control.

In the absence of EWG, removing $\mathrm{N}$ ( $N$ LOF) resulted in intermediate numbers of boutons compared to wild type and ewg LOF ( $p<0.0001$ for bar 5 compared with bar 1 and 2, Figure 7a). The increase in bouton numbers in N LOF (bar 5 compared with bar 2) is not additive to the numbers observed in the absence of EWG (bar 2 compared to bar 1, as seen for AP1 overexpression, see below), suggesting that regulation of synaptic growth by $\mathrm{N}$ is not independent of ewg and indicating that part of the $\mathrm{N}$ signal is required for the full effect seen in ewg LOF. Overexpression of $\mathrm{N}$ ( $N$ GOF) in the absence of EWG resulted in intermediate numbers of boutons compared to wild type and ewg LOF $(p<0.0001$ for bar 7 compared with bars 1 and 2, Figure 7a).

Overexpression of $w g$ increased bouton numbers $(p<0.0001$ for bar 1 compared with bar 8, Figure $7 \mathrm{~b}$ ), as previously observed [43]. Overexpression of pan also resulted in increased bouton numbers $(p<0.0001$ for bar 1 compared with bar 10, Figure 7b), demonstrating that the canonical $w g$ pathway operates presynaptically to stimulate synaptic growth.

In the absence of EWG, overexpression of both $w g$ and pan were epistatic to ewg LOF and bouton numbers were significantly reduced compared to ewg LOF ( $p \leq 0.0001$ for bar 2 compared with bars 9 and 11, Figure 7b).

\section{AP-I and TGF-? act together with erect wing in synaptic growth regulation}

The fos and jun heterodimer AP-1, and TGF- $\beta$ signaling comprise two other known pathways involved in regulating synaptic growth $[4,5,7,8]$. Both AP-1 and TGF- $\beta$ stimulate synaptic growth compared to wild type as evident either by overexpression of fos and jun together $(p<0.0001$ for bar 1 compared with bar 12, Figure $7 \mathrm{c}$ ) and an activated BMP type I receptor ( $t k v A$, from two copies of $U A S-t k v A, p<0.0001$ for bar 1 compared with bar 16, Figure $7 \mathrm{~d}$ ), or by removal of AP1 activity through overexpression of a dominant negative form of jun (junBZ, $p<0.0001$ for bar 1 compared with bar 14 , Figure $7 \mathrm{c}$ ), or in the BMP type II receptor mutant wishful thinking (wit, $p<0.0001$ for bar 1 compared with bar 18, Figure $7 \mathrm{~d}$ ), which is largely in agreement with previous observa- 


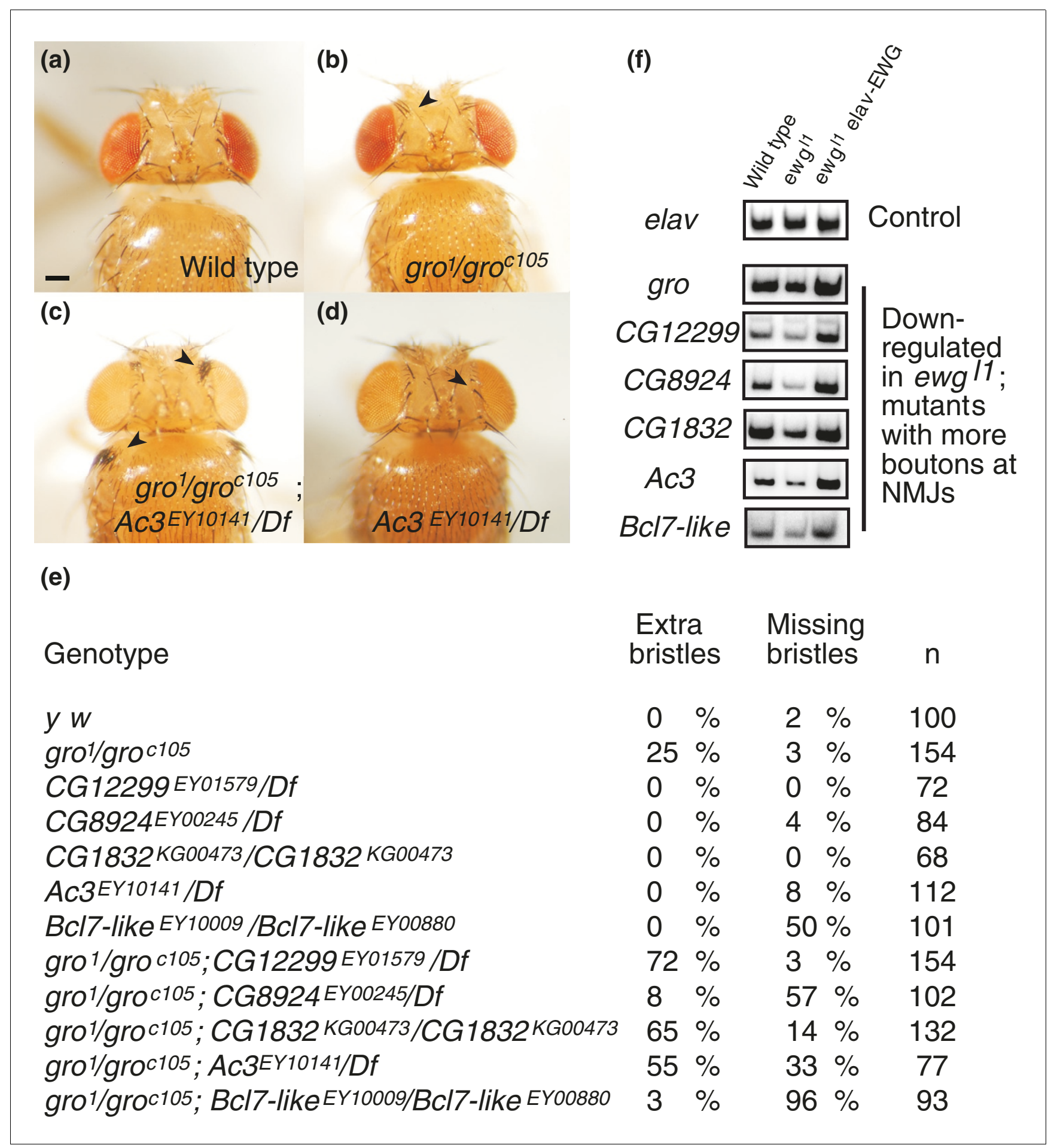

\section{Figure 6}

Validation of functional relationships of ewg co-regulated genes by genetic interactions. (a-d) Top view of head and thorax of wild type, gro and Ac3 mutants, and gro Ac3 double mutants. Note the strong overproliferation of frontal bristle on the head and humeral bristles on the thorax of gro Ac3 double mutants compared to gro mutants (arrowheads). Some Ac3 mutants, as shown in (d), have a reduced number of frontal bristles (arrowhead). Deficiencies used are listed in Table S2 in Additional data file I. The scale bar in (a) represents $100 \mu \mathrm{m}$. (e) Analysis of frontal bristle numbers in single and double mutants of genes down-regulated in ewg/lmutants with a synaptic overgrowth phenotype. Note that in all double mutants tested the frontal bristle phenotype is either enhanced or suppressed. Deficiencies used are listed in Table S2 in Additional data file I. (f) Quantitative RT-PCR of genes downregulated in ewgl/mutants with a synaptic overgrowth phenotype. PCR products using $32 \mathrm{P}$ labeled forward primers from cycle 26 were analyzed on $6 \%$ polyacrylamide gels. elav: control (cycle 28). 
tions $[4,5,7,8]$. Overexpression of either fos or jun alone has no effect on synaptic growth [4] (and data not shown).

Next, we wanted to define how these two pathways relate to ewg mediated regulation of synaptic growth. In the absence of EWG, overexpression of AP-1 is additive and further increases bouton numbers significantly $(p<0.0001$ for bar 13 compared with bars 2 and 12, Figure 7c). Inhibiting AP-1 function by expressing the dominant negative junBZ completely removes the stimulatory effect of ewg LOF ( $p<$ o.ooo1 for bar 15 compared with bars 2 and 13, and non-significant for bar 15 compared to bar 14, Figure 7c), suggesting that AP-1 functions downstream of ewg.

Overexpression of $t k v A$ (from two copies of $U A S$-tkvA) in $e w g$ LOF resulted in intermediate numbers of boutons compared to wild type and ewg LOF ( $p<0.0001$ for bar 17 compared with bars 1 and 2, Figure $7 d$ ), indicating that the TGF- $\beta$ signaling pathway does not act independent of ewg in synaptic growth regulation. Removal of the BMP type II receptor wit significantly reduced bouton numbers in ewg LOF ( $p<$ 0.0001 for bar 19 compared with bars 2 and 17, Figure $7 d$ ). The strong reduction of bouton numbers in wit mutants in ewg LOF compared to wild type ( $p<0.0001$ for bar 19 compared with bar 1 , Figure $7 d$ ) further suggests that TGF- $\beta$ signaling also includes a component that acts downstream of ewg.

\section{Discussion}

Several pathways have been identified that stimulate synaptic growth at NMJs of Drosophila larvae (Wnt/Wingless, TGF$\beta /$ BMP and jun kinase) [2-4]. Overexpression of AP-1 [4] and mutants in regulatory genes involved in Wnt/Wingless and TGF- $\beta$ /BMP pathways (spinster, highwire, shaggy and the proteasome) [9,47-49] can increase bouton numbers, suggesting that synaptic growth is regulated through the balance of stimulatory and restrictive signals. Here, we have identified such a restrictive role for the transcription factor EWG and, through the analysis of EWG-regulated genes, for the $\mathrm{N}$ pathway in the regulation of synaptic growth. Using genetic mosaics, we further demonstrate that EWG's role in synaptic growth regulation is cell-autonomous, suggesting that the transcriptional regulator EWG mediates this restrictive effect through the alteration of transcription presynaptically.

Analysis of genes differentially expressed in ewg ${ }^{l}$ mutants revealed a rather unexpected set of genes involved in synaptic growth regulation, besides an expected number of metabolic genes due to homology of EWG to human NRF-1 [50]. Most genes that could account for the phenotype of ewglimutants, and that are thus expressed in the nervous system, are involved in transcriptional and post-transcriptional regulation of gene expression. Although changes of transcript levels in ewg ${ }^{l}$ mutants were mostly moderate, their significance was validated through mRNA profiling with rescued ewglimutants under the same conditions of RNA preparation and microarray hybridization. In addition, differences in gene expression in ewg ${ }^{l}$ mutants were validated using quantitative RT-PCR and biochemical assays with regard to predicted changes in glycogen levels based on differential regulation of genes involved in gluconeogenesis (for example, Pepck; Additional data file 1). Furthermore, genetic interaction experiments in double mutants with increased bouton numbers support that these co-regulated genes are functionally connected in regulating synaptic growth.

The group of neuronal genes among those differentially regulated in ewg ${ }^{l l}$ mutants that have been demonstrated to have roles in synaptic growth or could account for it, is remarkably small. In particular, from the large number of cell adhesion molecules and cytoskeletal proteins present in the Drosophila genome only a handful is differentially regulated. Similar results have also been obtained in response to JNK and AP-1 signaling [15]. These results are in contrast to changes in gene expression induced by acute or chronically enhanced neuronal activity in Drosophila seizure mutants, which also result in synaptic overgrowth [51]. Here, the vast majority of differentially regulated genes are for cell adhesion molecules and cytoskeletal proteins or their regulators, and genes involved in synaptic transmission and neuronal excitability; transcriptional or post-transcriptional regulators comprise only a minor portion. These differences could be explained by separate pathways regulating growth independent of neuronal activity $[36,52]$ (and this study).

Particularly striking is the large number of genes involved in RNA processing among genes differentially expressed in $e w g^{l}$ mutants. Although local regulation of gene expression is required in growth cones of navigating axons, a prominent role for pre-synaptic regulation of gene expression at the RNA level is only just emerging [53], but is a hallmark of post-synaptic plasticity [29,54]. Several RNA binding proteins have been implicated in memory storage $[23,55,56]$. osk and CPSF (cleavage and polyadenylation specificity factor) are among the genes differentially regulated in ewg ${ }^{l}$ mutants. Other genes involved in RNA processing differentially regulated in ewg ${ }^{l}$ mutants comprise the whole spectrum of regulation at the post-transcriptional level, from nuclear organization (otefin), alternative pre-mRNA processing (Pinin, CPSF, Rox8) and export/import (Segregetion distorter, Nxf2, CG11092, Karyopherin, Transportin) to transport, localization and translation (oskar, swallow, ribosomal protein genes $S_{5}$ and $R p l 24)$, and likely also include the regulation of mRNA stability (Rox8).

An intriguing connection between ewg and signaling pathways involved in regulating synaptic growth is indicated by differentially regulated components of the $\mathrm{Wg}$ and $\mathrm{N}$ pathways (gro and Hairless) [39,41,42,57] in ewglimutants. Consistent with a role of the co-repressor gro in $\mathrm{Wg}$ and $\mathrm{N}$ 
mediated transcriptional regulation of synaptic growth, Wg and $\mathrm{N}$ signaling pathways do not operate independently of $e w g$ in genetic interaction experiments. The transcriptional regulatory networks of EWG, Wg and $\mathrm{N}$ seem to be highly interwoven. Overexpression of pan, the transcriptional mediator of canonical Wg signaling, which is repressed by gro, does not lead to a further expansion of synaptic growth in ewg mutants, suggesting a requirement for ewg-regulated genes. This effect could be mediated by deregulated $\mathrm{N}$ signaling, which is also repressed by gro, but antagonistic to Wg in synaptic growth. Thus, removal of gro, as in ewg, will relieve the repressive effect of $\mathrm{N}$ and antagonize the stimulatory effect of pan. In the complementary situation, removal of $\mathrm{N}$ increased bouton numbers further in the absence of EWG, which is consistent with an increase in $\mathrm{Wg}$ signaling as a result of downregulated gro in ewg mutants. Antagonism between $\mathrm{N}$ and Wg pathways has also been found in wing discs, where $\mathrm{N}$ inhibits armadillo ( $\mathrm{arm}$ ), the transcriptional co-activator of canonical Wg signaling [58]. Intriguingly, gro has also been found to be a target of receptor tyrosine kinase signaling and, thus, can combine additional pathways with $\mathrm{N}$ and $\mathrm{Wg}$ signaling [59,6o]. In addition to transcriptional hierarchies, chromatin remodeling has also been implicated in synaptic plasticity [61]. Strikingly, CG6297, a Drosophila homologue of the histone deacetylase RPD3, is differentially expressed in ewg ${ }^{l i}$ mutants and physically interacts with gro [62].

How ewg exerts its effect on TGF- $\beta$ signaling is less clear. A prominent regulatory step in this pathway is the regulated degradation of the SMAD co-factor Medea by Highwire [5]. Several genes involved in regulating protein stability are differentially down-regulated in ewg mutants (CG6759, CG3431, CG4973, CG7288, CG3455, CG9327 and CG9556). Lower expression levels of these genes might interfere with stabilization of Medea and explain why the effect of activated TGF- $\beta$ signaling is not additive in the absence of EWG ( $t k v A$ GOF ewg LOF). Bouton numbers in wit null mutants are marginally increased in the absence of EWG, suggesting further that genes regulated by SMADs are involved in mediating synaptic overgrowth in ewglimutants. Potentially, ewg could also regulate TGF- $\beta$ signaling through the endosomal pathway involving spinster and/or spichthyin [9,63].
Functionally related genes have been shown to be co-regulated [37], suggesting additional ELAV targets in EWG-regulated gene networks. Indeed, ELAV negatively regulates alternative splicing of the penultimate exon in armadillo (arm) [19]. Exclusion of this exon, which truncates the carboxyl terminus of arm, reduces $\mathrm{Wg}$ signal transduction, which is in agreement with ewg's antagonistic role relative to Wg signaling. Another known ELAV target gene is neuroglian ( $\mathrm{nrg}$ ), where a role in synapse formation has recently been demonstrated in the giant fiber system [64]. Taken together, the establishment of a gene network regulated by EWG will now serve as valuable tool to identify further ELAV regulated modules that shape the synapse.

\section{Conclusion}

The transcription factor EWG is a major target of the RNA binding protein ELAV, which regulates EWG protein expression via a splicing mechanism. EWG is required pre-synaptically and cell-autonomously at third instar neuromuscular junctions to restrict synaptic growth, demonstrating that restrictive activities at gene expression levels are also required for synaptic growth regulation. EWG mediates regulation of synaptic growth primarily by increasing transcript levels of genes involved in transcriptional and post-transcriptional regulation of gene expression. Genes at the end of the gene expression hierarchy (effector genes) represent only a minor portion of EWG-regulated genes. Since analysis of mutants in genes differentially regulated in ewg ${ }^{l}$ mutants revealed that these genes are involved in both stimulatory and restrictive pathways of synaptic growth, and since ewg genetically interacts with a number of signaling pathways (Wingless, Notch, TGF- $\beta$ and AP-1), our results suggest that synaptic growth in Drosophila is regulated by the interplay of multiple signaling pathways rather than through independent pathways.

\section{Materials and methods Fly genetics, recombinant DNA technology and microarrays}

Fly breeding, genetics and P-element mediated transformation of Drosophila, and recombinant DNA technology were

Figure 7 (see following page)

erect wing integrates cellular signaling to regulate synaptic growth. (a-d) Genetic interaction of ewg with known signaling pathways in synaptic growth regulation. Synaptic growth was analyzed at third instar NMJs by quantifying type Ib boutons at muscle 13 of ewglleFeG clones (white bars and '-' at the bottom of the column) or of ewgll $\mathrm{eFeG}$ clones in the presence of an ewg wild-type copy (grey bars and ' + ' at the bottom of the column) in combination with either transgenes for UAS constructs or transheterozygous combinations of mutant alleles (wit ${ }^{A I} /$ wit $^{B I I}$ ) as described for Figure I. Wild type (bar I), ewg loss of function (LOF, bar 2) and ewg gain of function (GOF, black bars, bar 3) were compared to LOF and GOF mutants in Notch (a), Wingless (b), AP-I (c) and TGF-?/BMP (d) pathways. Overexpression of N is shown in the presence of both ewg copies ('++' at the bottom of the column), as one ewg copy in the presence of excess $\mathrm{N}$ does not result in a significant increase of bouton numbers compared to wild type. For both $N$ and tkvA, two copies of UAS transgenes were used; a single copy did not significantly alter bouton numbers. Shown are means of bouton numbers with standard errors ( $\mathrm{n}=\mathrm{I}-\mathrm{-23}$, numbers at the bottom of bars). Bars are numbered below the $\mathrm{x}$-axis. Statistical significance of differences from comparisons with wild type is shown on top of bars $(* * * p<0.0001$, $* * p<0.005$, n.s. for non significant). Other relevant comparisons are marked by horizontal bars with the statistical significance indicated on the side. 
(a)

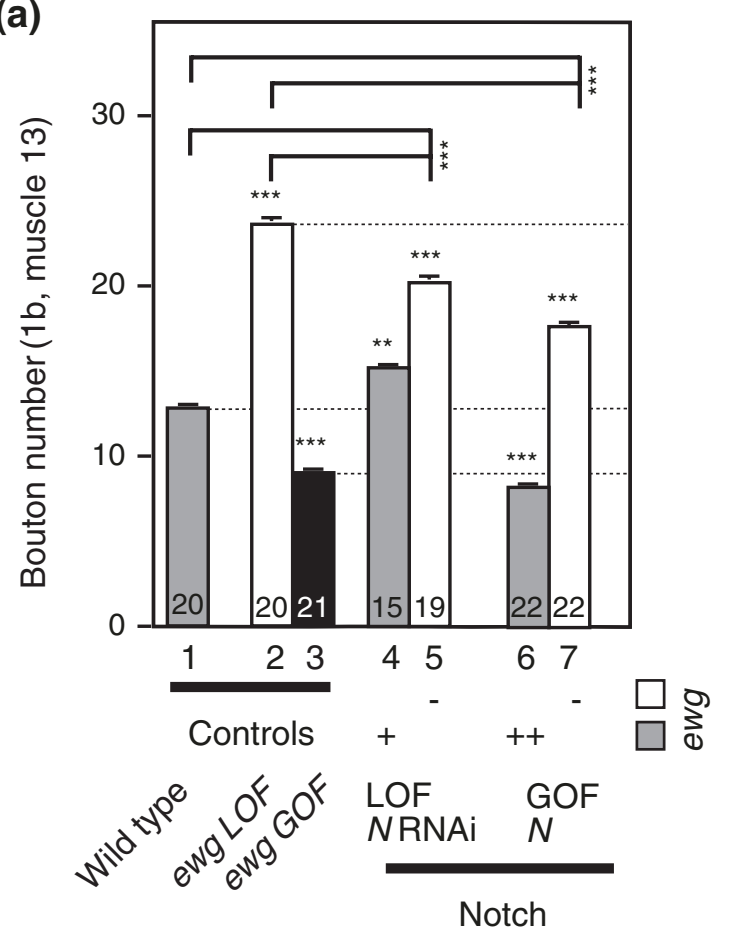

(c)

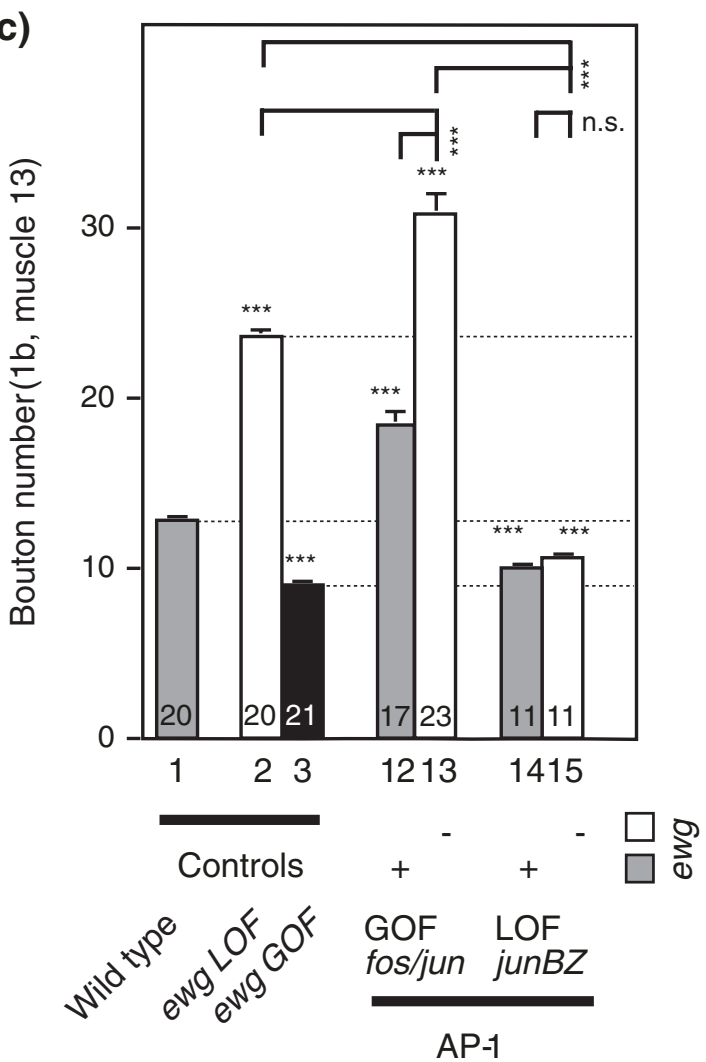

(b)

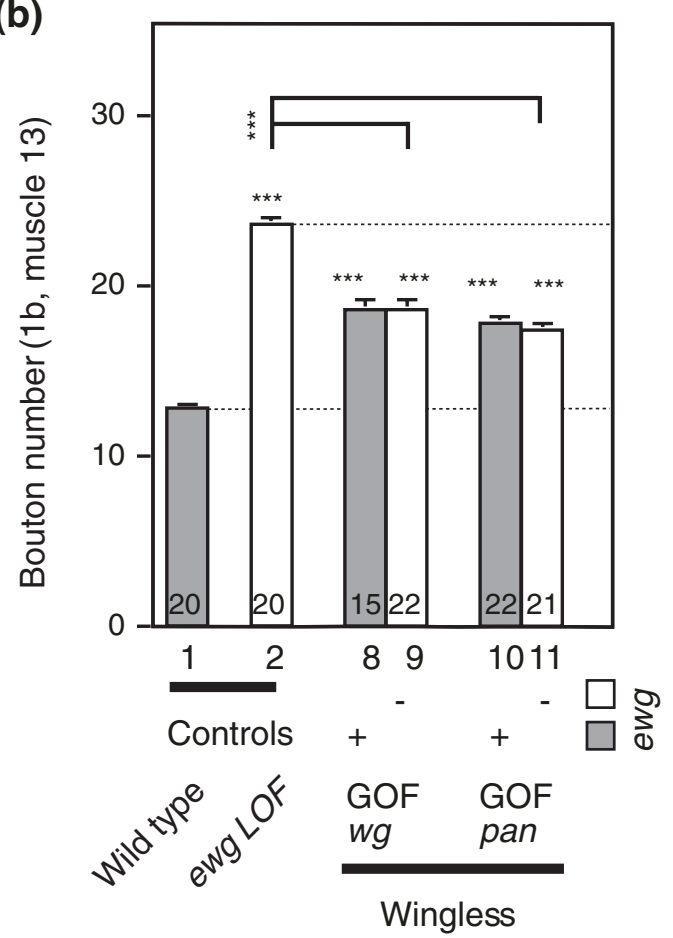

(d)

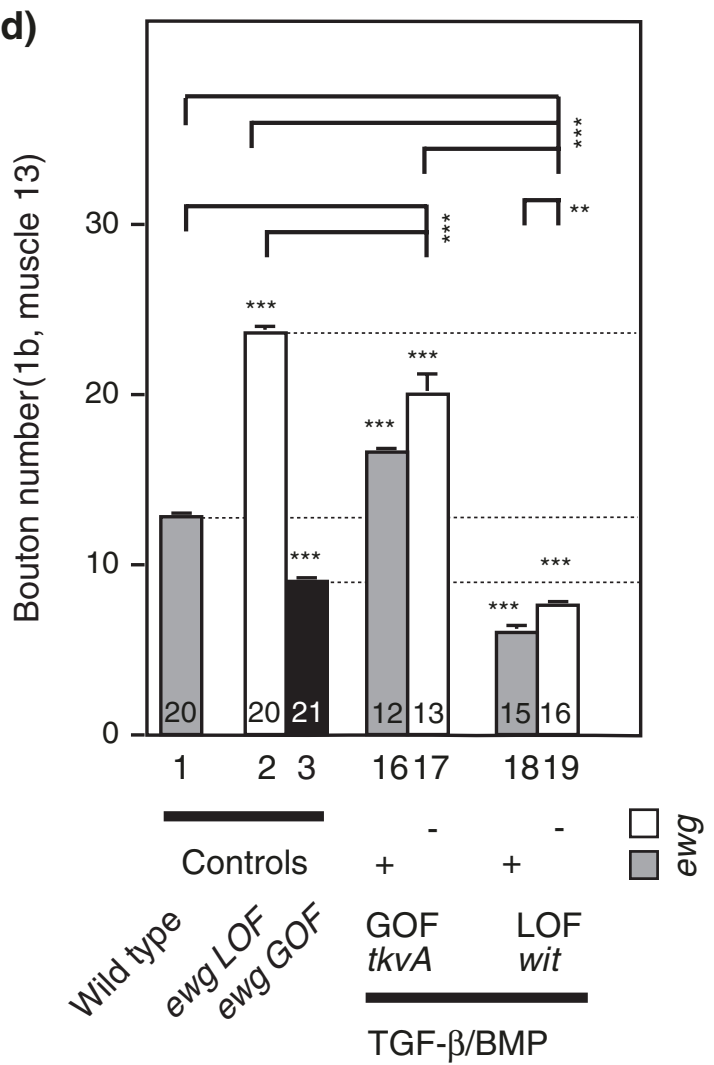

Figure 7 (see legend on previous page) 
done according to standard procedures as detailed in Soller and White [21] and Soller et al. [65]. In all experiments the $e w g$ NS isoform was used [24]. The $e F e G$ construct $P\{w+=$ elav-FRT-EWG-FRT-GAL4\} is basically the same as the $E W G^{N S}$ construct [25] except that the ewg cDNA is flanked by FRT sites followed by the coding sequence of the yeast GAL4 transcription factor.

For cloning of the $e \mathrm{Fe} G$ construct, the $3.5 \mathrm{~kb}$ elav promoter [25] was cloned into a linker modified CaSpeR 4 (Drosophila Genomics Resource Center, Bloomington, IN, USA) with a blunt EcoRI site and NotI site to generate the construct C4MMelav2. The 5' FRT site was added to the ewg gene by $\begin{array}{llll}\text { nested } & \text { PCR with primers } & \text { FRTewgF1 }\end{array}$ (AGAAAGTATAGGAACTTCAGAGCGCTTTTGAAGCTAgcccac cgccaaactggccaccacaagc; the ewg sequence is indicated in small letters and restriction sites are underlined) and FRTewgF2

(CGGGGATCTTGAAGTTCCTATTCCGAAGTTCCTATTCTCT AGAAAGTATAGGAACTTCAGAGCGC) and ewg3cR1Spe (GGAACTAGTCAACACCTTGAACCTGGGCAGTTGTAC-

CATCC) and cloned into C4MMelav2 with a blunt NotI site and SpeI site to generate C4MMelavFRTewg. For cloning of the 3 ' part of $e F e G$, a HpaI-EcoRI fragment encoding the 3 ' part of the ewg cDNA was cloned into pBluescript (Stratagene, Cedar Creek, TX, USA) cut with EcoRV and EcoRI to generate $S C_{3} H E$. Subsequently, the 3' FRT site was cloned into $\mathrm{SC}_{3} H E$ cut with EcoRI and SacII with two oligonucleotides (FRT-A EcoRI x NotI, SpeI, SacII: AATTCCGGGGATCTTGAAGTTCCTATTCCGAAGTTCCTAT TCTCTAGAAAGTATAGGAACTTCAGAGCGCTTTT-

GAAGCT GCGGCCGCACTAGTGC and FRT-B: ACTAGTGCGGCCGCAGCTTCAAAAGCGCTCTGAAGTTCC TATACTTTCTAGAGAATAGGAACTTCGGAATAGGAACTTCA AGATCCCCGG) after the ewg 3' untranslated region (UTR) to generate $S_{3} H E F R T$. GAL4 with the hsp7o 3' UTR from pGaTN (Drosophila Genomics Resource Center) was cloned with NotI and SpeI into SC3HE FRT to generate $e F G$. From $e F G$, the 3 ' part of $e w g$, the FRT site and the GAL were cloned with Acc65I and SpeI into C4MMelavFRTewg to generate the $e \mathrm{FeG}$ construct.

For the analysis of synaptic growth in EWG deficient neurons, two independent inserts of the $e \mathrm{Fe} G$ construct on the $\mathrm{X}$ and third chromosomes that fully rescue ewg ${ }^{l 1}$ mutants were used. To induce clones with $e F e G$ transgenes, 14-18 h old embryos from $e w g^{l} e F e G$ females crossed with males carrying $h s-f l p$ UAS-CD8::GFP (P\{hsFLP\}38, P\{UAS-mCD8::GFP.L $\} L L 5$ $[66,67])$ on the second chromosome were heat shocked for 45 minutes at $35^{\circ} \mathrm{C}$, rested for 45 minutes at room temperature and incubated for another 45 minutes at $37^{\circ} \mathrm{C}$. For genetic interaction experiments, the ewgle $\mathrm{Fe} G$ and $h s-f l p U A S-$ CD8::GFP chromosomes were combined with the following $U A S$ transgenes or mutants (from Bloomington stock center, Bloomington, IN, USA) or as noted: $U A S-w g$ (second or third, $P\{w[+m C]=U A S-w g . H . T: H A 1\} 6 C$ and $P\{w[+m C]=$
$U A S-w g . H . T: H A 1\} 3 C$ [45]), UAS-pan (second or third, $P\{w$ $[+m C]=U A S-p a n . d T C F\} 24$ and $P\{w[+m C]=U A S-$ pan.dTCF 4 [45]), UAS-N-RNAi $i_{i}$ (second and/or third, $P\{w$ $[+m C]=U A S-N . d s R N A . P\} 14 A$ and $P\{w[+m C]=U A S-$ N.dsRNA.P\}9G [13]), UAS-N (second and/or third, gift form S Artavanis-Tsakonas [68]), UAS-tkvA (second and/or third, gift from M O'Connor [7]), UAS-junBZ (second or third, $P\{J b z\} 1$ and $P\{J b z\} 10$ [69]), UAS-fos (P\{UAS-Fra\}, second [69]), UAS-jun (P\{UAS-Jra\}2, third [69]) and wit ${ }^{A 12}$ with $w_{i}{ }^{B 11}$ [8], UAS-Tetanustoxin (gift from S Sweeney, $P\{U A S$ TeTxLC.tnt\}, CNT-E, second [70]). Overexpression of UAS$w g, U A S-p a n, U A S-N-R N A i$ and $U A S-N$ with elav-GS-GAL4 (third, $P\{$ elav-Switch. $O\}$ [27]) resulted in significant changes in bouton numbers comparable with overexpression with recombined $\mathrm{eFe}$ compared to wild type.

The elav-NRF-1 construct was made by exchanging the ewg open reading frame (ORF) in elav-EWG with the ORF of NRF-1 as follows. The NRF-1 ORF was amplified by PCR with primers NRF-F1 (TAGAGCGGCCGCTCGAGAATTCtttacgtggtcctttatttg) and NRF-R1 (CATGCCTTCTATGGGCTCCAgTCACTGTTCCAATGTCACCACCTC) from a cDNA clone (gift from R Scarpulla [18]), cut with NotI and combined with the 3' UTR of ewg amplified by PCR with primers ewgUTR-F1 (ctggagcccatagaaggcatg) and M13rev (GGAAACAGCTATGACCATG) from the ewg cDNA clone in pBluscript $\mathrm{SK}^{+}$cut with SpeI and with the C4MMelav2 cut with NotI and SpeI in a three way ligation to generate $C 4 M M e l a v 2 N R F-1$. NRF-1 expression was verified in transgenes by western blots. Inserts of elav-NRF-1 on the second and third chromosomes were used. elav-ELAV is the elav ORF under the control of the endogenous promoter followed by an a-tubulin 3' UTR, and the elav-NRF-1 insert on the second chromosome was used [25]. For the $U A S-e w g$ construct, the NS isoform ( $E W G^{N S}$ ) including the ewg 3' UTR [25] was cloned with BamHI and SpeI into a modified pUAST [71] cut with BglII and SpeI where the SV40 3' UTR had been removed. Conditional overexpression of EWG from $U A S-e w g$ (third) with elav-GSGAL4 (elav-GeneSwitch-GAL4 [27]) (third) was induced by adding RU486 (Mifepristone, Sigma, St Louis, MI, USA) in $100 \mu \mathrm{l}$ of $50 \%$ ethanol to larvae two days before dissection [27]. The elav alleles used were elav ${ }^{\text {ts1 }}$, a temperature sensitive allele, and elave5, a null allele [71]. Mutants used in genes differentially regulated in ewg $g^{l 1}$ mutants are listed in Table S2 in Additional data file 1 and were obtained from Bloomington, Harvard and Tübingen stock centers as indicated in Flybase [72].

Embryos for microarray analysis were produced by crossing ewgli $/ C 155-G A L 4 ; U A S-G F P /+$ females to C155-GAL4; UASGFP males $\left(P\{\right.$ GawB $\}$ elav ${ }^{155} ; \quad P\{U A S-G F P . S 65 T\} T 2$ [65,73]). The X-chromosomal C155-GAL4 enhancer trap was inserted in the neighboring elav gene and drives GFP expression in neurons and neuroblast [65]. From the progeny of this cross, non-GFP expressing embryos, which are male, were then hand-picked 16-18 $\mathrm{h}$ after egg laying and RNA was 
extracted from pools of 50 embryos with Trizol (Invitrogen, Carlsbad, CA, USA). Pooled RNA from a total of 300 embryos was then reverse-transcribed with an oligo-dT primer containing a $\mathrm{T} 7$ promoter and, after the synthesis of the second strand, linearly amplified by in vitro transcription with $\mathrm{T}_{7}$ RNA polymerase and labeled with biotinylated NTPs according to the manufacturers instructions (Genechip Protocol for Eukaryotic Target preparation, Affymetrix, Santa Clara, CA, USA) yielding between 20 and $50 \mu$ of RNA. Amplified RNA $(15 \mu \mathrm{g})$ including spike controls was hybridized to Affymetrix Drosophila genome arrays Version X using the Affymetrix Gene Chip Instrument System overnight at $42^{\circ} \mathrm{C}$. Arrays were washed and stained with streptavidin-phycoerythrin before scanning on an Affymetrix Gene Chip scanner.

Quantitative RT-PCR was done with 5' ${ }^{32} \mathrm{P}$ labeled forward primers and PCR products from unsaturated cycles $(24,26$, 28 or 30 depending on expression levels of a particular gene) were analyzed on $6 \%$ polyacrylamide gels essentially as previously described [19]. Primer sequences are available upon request.

\section{Microarray data analysis}

Gene chip data were analyzed using the software packages MAS version 5 (Affymetrix) and dChip. Scanned data were first processed with MAS to convert raw image files (.DAT) to probe signal values files (.Cel). Probe signal files were normalized across samples using dChip invariant set method. Summary values for each probe set were calculated with PMonly model in dChip. Microarray data have been deposited in MIAMExpress [74] under the accession number E-MEXP1312.

\section{Western blotting, RNA in situ hybridization, immunostaining and statistics}

Western blotting was done as previously described [24]. Quantification of western blots was done with Quantity ONE 4.2.3 (Bio-Rad, Hercules, CA, USA). RNA in situ hybridizations were done according to the BDGP protocol, or obtained from the BDGP web page [75]. For the analysis of NMJs, wandering third instar larvae were dissected in phosphate-buffered saline and fixed with $4 \%$ formaldehyde for 30 minutes. The following antibodies were used: anti-DSYT (1:200; gift from T Littelton [26]), anti-DLG (1:100; gift from V Budnik [76]), anti-CSP (1:100; gift from K Zinsmaier [77]), anti-Nc82 (1:6; Developmental Studies Hybridoma Bank), anti-Highwire (1:6; Developmental Studies Hybridoma Bank), Mab22C10 (1:200; Developmental Studies Hybridoma Bank), FITC conjugated anti-HRP (1:200; Cappel, Cochranville, PA, USA), FITC conjugated anti-CD8 (1:200; Cappel). FITC, TRITC (Jackson Labs, Bar Harbor, MA, USA) and Cascade Blue (Molecular Probes, Eugene, OR, USA) conjugated secondary antibodies were used 1:200. Confocal images were acquired at $18^{\circ} \mathrm{C}$ using a Leica TCS SP2 confocal scanning microscope with a Plan APO HC $10 \times 0.4$ numerical aperture objective for eye discs, or under oil with a Plan APO HCX 63 $\times 1.4$ numerical aperture (NMJs) or a Plan APO HCX $100 \times$ 1.4 numerical aperture (single boutons) objective and Leica software. Image files were converted to TIFF and merged using Photoshop CS2 (Adobe). Levels of individual channels were adjusted where applicable to maximize pixel range. Flies were photographed with a digital camera (Nikon) on a Leica Stereoscope at $3 \times$ magnification. Statistical analysis of bouton numbers was done with ANOVA followed by post hoc analysis with Fisher's PLSD (protected least significant difference) for multiple comparisons, or with $t$-test for two samples, using StatView.

\section{Abbreviations}

BDGP, Berkeley Drosophila Genome Project; BMP, bone morphogenetic protein; GFP, green fluorescent protein; LOF, loss of function; N, Notch; NMJ, neuromuscular junction; ORF, open reading frame; TGF, transforming growth factor; UTR, untranslated region.

\section{Authors' contributions}

IH and MS conceived the work, and designed and performed the experiments. KW gave advice and helped with the interpretation of results and writing of the paper. MS wrote the paper.

\section{Additional data files}

The following additional data are available with the online version of this paper. Additional data file 1 includes supplemental materials and methods, Figures S1-S3 and Tables S1S3.

\section{Acknowledgements}

We thank S. Artavanis-Tsakonas, J. Hodge, J. Jiang, M. O'Connor, H. Keshishian, U. Schäfer, S. Sweeney, and the Bloomington, Harvard (Exelixis) and Tübingen Stock Centers for fly lines, V, Budnik, T. Littleton, K. Zinsmaier and the Developmental Hybridoma Bank for antibodies, R. Scarpulla for NRF-I cDNA and antibodies, members of the Rosbash lab for help with microarrays, the Berkeley Drosophila Genome Project for embryonic expression patterns, $\mathrm{H}$. Briegel for lipid and glycogen measurement protocols, and L. Griffith and P. Sengupta for comments on the manuscript. This work was supported by National Institute of Health grants POI NS 44232, SI0 RRI 6708 and 5 P30 NS 0457I3.

\section{References}

I. Bailey $\mathrm{CH}$, Kandel ER, Si K: The persistence of long-term memory: a molecular approach to self-sustaining changes in learning-induced synaptic growth. Neuron 2004, 44:49-57.

2. Packard M, Mathew D, Budnik V: Wnts and TGF beta in synaptogenesis: old friends signalling at new places. Nat Rev Neuros $c i$ 2003, 4: II3-120.

3. Marques G: Morphogens and synaptogenesis in Drosophila. J Neurobiol 2005, 64:417-434.

4. Sanyal S, Sandstrom DJ, Hoeffer CA, Ramaswami M: AP-I functions upstream of CREB to control synaptic plasticity in Drosophila. Nature 2002, 416:870-874.

5. McCabe BD, Hom S, Aberle H, Fetter RD, Marques G, Haerry TE, Wan H, O'Connor MB, Goodman CS, Haghighi AP: Highwire regulates presynaptic BMP signaling essential for synaptic 
growth. Neuron 2004, 41:891-905.

6. McCabe BD, Marques G, Haghighi AP, Fetter RD, Crotty ML, Haerry TE, Goodman CS, O'Connor MB: The BMP homolog Gbb provides a retrograde signal that regulates synaptic growth at the Drosophila neuromuscular junction. Neuron 2003, 39:24I-254.

7. Marques G, Bao H, Haerry TE, Shimell MJ, Duchek P, Zhang B, O'Connor MB: The Drosophila BMP type II receptor Wishful Thinking regulates neuromuscular synapse morphology and function. Neuron 2002, 33:529-543.

8. Aberle H, Haghighi AP, Fetter RD, McCabe BD, Magalhaes TR, Goodman CS: wishful thinking encodes a BMP type II receptor that regulates synaptic growth in Drosophila. Neuron 2002, 33:545-558.

9. Sweeney ST, Davis GW: Unrestricted synaptic growth in spinster-a late endosomal protein implicated in TGF-beta-mediated synaptic growth regulation. Neuron 2002, 36:403-416.

10. Budnik V, Gramates LS: Neuromuscular Junctions in Drosophila San Diego: Academic press; 1999.

II. Yoon K, Gaiano N: Notch signaling in the mammalian central nervous system: insights from mouse mutants. Nat Neurosci 2005, 8:709-7I5.

12. Ge X, Hannan F, Xie Z, Feng C, Tully T, Zhou H, Xie Z, Zhong Y: Notch signaling in Drosophila long-term memory formation. Proc Natl Acad Sci USA 2004, 101 : $10172-10176$.

13. Presente A, Boyles RS, Serway CN, de Belle JS, Andres AJ: Notch is required for long-term memory in Drosophila. Proc Natl Acad Sci USA 2004, I01:1764-1768.

14. Collins CA, Wairkar YP, Johnson SL, DiAntonio A: Highwire restrains synaptic growth by attenuating a MAP kinase signal. Neuron 2006, 51:57-69.

15. Etter PD, Narayanan R, Navratilova Z, Patel C, Bohmann D, Jasper H, Ramaswami M: Synaptic and genomic responses to JNK and AP-I signaling in Drosophila neurons. BMC Neurosci 2005, 6:39.

16. Hoeffer CA, Sanyal S, Ramaswami M: Acute induction of conserved synaptic signaling pathways in Drosophila melanogaster. J Neurosci 2003, 23:6362-6372.

17. DeSimone SM, White K: The Drosophila erect wing gene, which is important for both neuronal and muscle development, encodes a protein which is similar to the sea urchin P3A2 DNA binding protein. Mol Cell Biol 1993, 13:364I-3649.

18. Virbasius CA, Virbasius JV, Scarpulla RC: NRF-I, an activator involved in nuclear-mitochondrial interactions, utilizes a new DNA-binding domain conserved in a family of developmental regulators. Genes Dev 1993, 7:2431-2445.

19. Koushika SP, Soller M, White K: The neuron-enriched splicing pattern of Drosophila erect wing is dependent on the presence of ELAV protein. Mol Cell Biol 2000, 20:1836-1845.

20. Soller M, White K: Elav. Curr Biol 2004, I 4:R53.

21. Soller M, White K: ELAV inhibits 3'-end processing to promote neural splicing of ewg pre-mRNA. Genes Dev 2003, 1 7:2526-2538.

22. Soller M, White K: ELAV multimerizes on conserved AU4-6 motifs important for ewg splicing regulation. Mol Cell Biol 2005, 25:7580-7591.

23. Pascale A, Gusev PA, Amadio M, Dottorini T, Govoni S, Alkon DL, Quattrone A: Increase of the RNA-binding protein HuD and posttranscriptional up-regulation of the GAP-43 gene during spatial memory. Proc Natl Acad Sci USA 2004, 10I: I 2 17- 222.

24. Koushika SP, Soller M, DeSimone SM, Daub DM, White K: Differential and inefficient splicing of a broadly expressed Drosophila erect wing transcript results in tissue-specific enrichment of the vital EWG protein isoform. Mol Cell Biol 1999, 19:3998-4007.

25. DeSimone S, Coelho C, Roy S, VijayRaghavan K, White K: ERECT WING, the Drosophila member of a family of DNA binding proteins is required in imaginal myoblasts for flight muscle development. Development 1996, 122:31-39.

26. Littleton JT, Bellen HJ, Perin MS: Expression of synaptotagmin in Drosophila reveals transport and localization of synaptic vesicles to the synapse. Development 1993, I I 8:1077-1088.

27. Osterwalder T, Yoon KS, White BH, Keshishian H: A conditional tissue-specific transgene expression system using inducible GAL4. Proc Natl Acad Sci USA 200 I, 98: | 2596-1260।.

28. Yao KM, Samson ML, Reeves R, White K: Gene elav of Drosophila melanogaster: a prototype for neuronal-specific RNA binding protein gene family that is conserved in flies and humans. $J$ Neurobiol 1993, 24:723-739.

29. Steward O, Schuman EM: Compartmentalized synthesis and degradation of proteins in neurons. Neuron 2003, 40:347-359.

30. Venken KJ, Bellen HJ: Emerging technologies for gene manipulation in Drosophila melanogaster. Nat Rev Genet 2005, 6:167-I78.

31. Bellen HJ, Levis RW, Liao G, He Y, Carlson JW, Tsang G, Evans-Holm M, Hiesinger PR, Schulze KL, Rubin GM, Hoskins RA, Spradling AC: The BDGP gene disruption project: single transposon insertions associated with $\mathbf{4 0 \%}$ of Drosophila genes. Genetics 2004, 167:76I-781.

32. Thibault ST, Singer MA, Miyazaki WY, Milash B, Dompe NA, Singh CM, Buchholz R, Demsky M, Fawcett R, Francis-Lang HL, Ryner L, Cheung LM, Chong A, Erickson C, Fisher WW, Greer K, Hartouni SR, Howie E, Jakkula L, Joo D, Killpack K, Laufer A, Mazzotta J, Smith RD, Stevens LM, Stuber C, Tan LR, Ventura R, Woo A, Zakrajsek I, et al:: A complementary transposon tool kit for Drosophila melanogaster using P and piggyBac. Nat Genet 2004, 36:283-287.

33. Spradling AC, Stern D, Beaton A, Rhem EJ, Laverty T, Mozden N, Misra S, Rubin GM: The Berkeley Drosophila Genome Project gene disruption project: single P-element insertions mutating 25\% of vital Drosophila genes. Genetics 1999, I53:135-177.

34. Rorth P: A modular misexpression screen in Drosophila detecting tissue-specific phenotypes. Proc Natl Acad Sci USA 1996, 93:12418-12422.

35. Dubnau J, Tully T: Gene discovery in Drosophila: new insights for learning and memory. Annu Rev Neurosci 1998, 21:407-444.

36. Schuster CM, Davis GW, Fetter RD, Goodman CS: Genetic dissection of structural and functional components of synaptic plasticity. Neuron 1996, 17:641-654.

37. Banerjee N, Zhang MQ: Functional genomics as applied to mapping transcription regulatory networks. Curr Opin Microbiol 2002, 5:3 I3-317.

38. Jimenez G, Paroush Z, Ish-Horowicz D: Groucho acts as a corepressor for a subset of negative regulators, including Hairy and Engrailed. Genes Dev 1997, I I:3072-3082.

39. Barolo S, Stone T, Bang AG, Posakony JW: Default repression and Notch signaling: Hairless acts as an adaptor to recruit the corepressors Groucho and dCtBP to Suppressor of Hairless. Genes Dev 2002, 16:1964-1976.

40. Maier D, Marte BM, Schafer W, Yu Y, Preiss A: Drosophila evolution challenges postulated redundancy in the $E(s p l)$ gene complex. Proc Natl Acad Sci USA 1993, 90:5464-5468.

41. Cavallo RA, Cox RT, Moline MM, Roose J, Polevoy GA, Clevers H, Peifer M, Bejsovec A: Drosophila Tcf and Groucho interact to repress Wingless signalling activity. Nature 1998, 395:604-608.

42. Daniels DL, Weis WI: Beta-catenin directly displaces Groucho/ TLE repressors from Tcf/Lef in Wnt-mediated transcription activation. Nat Struct Mol Biol 2005, I 2:364-37I.

43. Packard M, Koo ES, Gorczyca M, Sharpe J, Cumberledge S, Budnik V: The Drosophila Wnt, wingless, provides an essential signal for pre- and postsynaptic differentiation. Cell 2002, I I I:319-330.

44. Brunner E, Peter O, Schweizer L, Basler K: pangolin encodes a LefI homologue that acts downstream of Armadillo to transduce the Wingless signal in Drosophila. Nature 1997, 385:829-833.

45. van de Wetering $M$ van de, Cavallo $R$, Dooijes $D$, van Beest $M$, van Es J, Loureiro J, Ypma A, Hursh D, Jones T, Bejsovec A, Peifer M, Mortin $M$, Clevers $\mathrm{H}$ : Armadillo coactivates transcription driven by the product of the Drosophila segment polarity gene dTCF. Cell 1997, 88:789-799.

46. Riese J, Yu X, Munnerlyn A, Eresh S, Hsu SC, Grosschedl R, Bienz M: LEF-I, a nuclear factor coordinating signaling inputs from wingless and decapentaplegic. Cell 1997, 88:777-787.

47. Wan HI, DiAntonio A, Fetter RD, Bergstrom K, Strauss R, Goodman CS: Highwire regulates synaptic growth in Drosophila. Neuron 2000, 26:313-329.

48. DiAntonio A, Haghighi AP, Portman SL, Lee JD, Amaranto AM, Goodman CS: Ubiquitination-dependent mechanisms regulate synaptic growth and function. Nature 200I, 4I 2:449-452.

49. Franco B, Bogdanik L, Bobinnec Y, Debec A, Bockaert J, Parmentier ML, Grau Y: Shaggy, the homolog of glycogen synthase kinase 3 , controls neuromuscular junction growth in Drosophila. J Neurosci 2004, 24:6573-6577.

50. Cam H, Balciunaite E, Blais A, Spektor A, Scarpulla RC, Young R, Kluger $Y$, Dynlacht BD: A common set of gene regulatory networks links metabolism and growth inhibition. Mol Cell 2004, 16:399-4II.

5I. Guan Z, Saraswati S, Adolfsen B, Littleton JT: Genome-wide tran- 
scriptional changes associated with enhanced activity in the Drosophila nervous system. Neuron 2005, 48:91-107.

52. Goold CP, Davis GW: The BMP ligand Gbb gates the expression of synaptic homeostasis independent of synaptic growth control. Neuron 2007, 56: I09-123.

53. Piper M, Holt C: RNA translation in axons. Annu Rev Cell Dev Biol 2004, 20:505-523

54. Sigrist SJ, Thiel PR, Reiff DF, Lachance PE, Lasko P, Schuster CM: Postsynaptic translation affects the efficacy and morphology of neuromuscular junctions. Nature 2000, 405: I062-1065.

55. Dubnau J, Chiang AS, Grady L, Barditch J, Gossweiler S, McNeil J, Smith P, Buldoc F, Scott R, Certa U, Broger C, Tully T: The staufen/ pumilio pathway is involved in Drosophila long-term memory. Curr Biol 2003, I 3:286-296.

56. Si K, Giustetto M, Etkin A, Hsu R, Janisiewicz AM, Miniaci MC, Kim $\mathrm{JH}$, Zhu $\mathrm{H}$, Kandel ER: A neuronal isoform of CPEB regulates local protein synthesis and stabilizes synapse-specific longterm facilitation in aplysia. Cell 2003, I I 5:893-904.

57. Maier D, Stumm G, Kuhn K, Preiss A: Hairless, a Drosophila gene involved in neural development, encodes a novel, serine rich protein. Mech Dev 1992, 38:|43-156.

58. Hayward P, Brennan K, Sanders P, Balayo T, DasGupta R, Perrimon N, Martinez Arias A: Notch modulates Wnt signalling by associating with Armadillo/beta-catenin and regulating its transcriptional activity. Development 2005, I32:1819-1830.

59. Cinnamon E, Helman A, Ben-Haroush Schyr R, Orian A, Jimenez G Paroush Z: Multiple RTK pathways downregulate Grouchomediated repression in Drosophila embryogenesis. Development 2008, I 35:829-837.

60. Orian A, Delrow JJ, Rosales Nieves AE, Abed M, Metzger D, Paroush Z, Eisenman RN, Parkhurst SM: A Myc-Groucho complex integrates EGF and Notch signaling to regulate neural development. Proc Natl Acad Sci USA 2007, I 04: I577I - I 5776.

61. Guan Z, Giustetto M, Lomvardas S, Kim JH, Miniaci MC, Schwartz JH, Thanos D, Kandel ER: Integration of long-term-memoryrelated synaptic plasticity involves bidirectional regulation of gene expression and chromatin structure. Cell 2002, i I I:483-493.

62. Chen G, Fernandez J, Mische S, Courey AJ: A functional interaction between the histone deacetylase Rpd3 and the corepressor groucho in Drosophila development. Genes Dev 1999, 13:2218-2230.

63. Wang X, Shaw WR, Tsang HT, Reid E, O'Kane CJ: Drosophila spichthyin inhibits BMP signaling and regulates synaptic growth and axonal microtubules. Nat Neurosci 2007, 10:177-185.

64. Godenschwege TA, Kristiansen LV, Uthaman SB, Hortsch M, Murphey RK: A conserved role for Drosophila Neuroglian and human LI-CAM in central-synapse formation. Curr Biol 2006 1 6:12-23.

65. Soller M, Haussmann IU, Hollmann M, Choffat $Y$, White K, Kubli E, Schafer MA: Sex-peptide-regulated female sexual behavior requires a subset of ascending ventral nerve cord neurons. Curr Biol 2006, 16:1771-1782.

66. Chou TB, Perrimon N: Use of a yeast site-specific recombinase to produce female germline chimeras in Drosophila. Genetics 1992, 1 31:643-653.

67. Lee T, Luo L: Mosaic analysis with a repressible cell marker for studies of gene function in neuronal morphogenesis. Neuron |999, 22:45|-46|.

68. Rebay I, Fehon RG, Artavanis-Tsakonas S: Specific truncations of Drosophila Notch define dominant activated and dominant negative forms of the receptor. Cell 1993, 74:319-329.

69. Eresh S, Riese J, Jackson DB, Bohmann D, Bienz M: A CREB-binding site as a target for decapentaplegic signalling during Drosophila endoderm induction. EMBO J 1997, 16:20|4-2022.

70. Sweeney ST, Broadie K, Keane J, Niemann H, O'Kane CJ: Targeted expression of tetanus toxin light chain in Drosophila specifically eliminates synaptic transmission and causes behavioral defects. Neuron 1995, 14:341-351.

7I. Brand $\mathrm{AH}$, Perrimon $\mathrm{N}$ : Targeted gene expression as a means of altering cell fates and generating dominant phenotypes. Development 1993, I | 8:401-4I5.

72. Flybase [http://flybase.bio.indiana.edu/]

73. Newsome TP, Asling B, Dickson BJ: Analysis of Drosophila photoreceptor axon guidance in eye-specific mosaics. Development 2000, I 27:85I-860.

74. MIAMExpress [http://www.ebi.ac.uk/arrayexpress]

75. BDGP [http://www.fruitfly.org/]
76. Lahey T, Gorczyca M, Jia XX, Budnik V: The Drosophila tumor suppressor gene dlg is required for normal synaptic bouton structure. Neuron 1994, 1 3:823-835.

77. Zinsmaier KE, Hofbauer A, Heimbeck G, Pflugfelder GO, Buchner S Buchner $E$ : A cysteine-string protein is expressed in retina and brain of Drosophila. J Neurogenet 1990, 7:15-29.

78. Scarpulla RC: Nuclear control of respiratory gene expression in mammalian cells. J Cell Biochem 2006, 97:673-683.

79. Verstreken P, Ly CV, Venken KJ, Koh TW, Zhou Y, Bellen HJ: Synaptic mitochondria are critical for mobilization of reserve pool vesicles at Drosophila neuromuscular junctions. Neuron 2005, 47:365-378.

80. Guo X, Macleod GT, Wellington A, Hu F, Panchumarthi S, Schoenfield M, Marin L, Charlton MP, Atwood HL, Zinsmaier KE: The GTPase dMiro is required for axonal transport of mitochondria to Drosophila synapses. Neuron 2005, 47:379-393.

8I. Wang P, Saraswati S, Guan Z, Watkins CJ, Wurtman RJ, Littleton JT: A Drosophila temperature-sensitive seizure mutant in phosphoglycerate kinase disrupts ATP generation and alters synaptic function. I Neurosci 2004, 24:45 I 8-4529.

82. Dorer DR, Rudnick JA, Moriyama EN, Christensen AC: A family of genes clustered at the Triplo-lethal locus of Drosophila melanogaster has an unusual evolutionary history and significant synteny with Anopheles gambiae. Genetics 2003, 165:613-62I.

83. Clements AN: The Biology of Mosquitos Volume I. London: Chapman and Hall; 1992. 